Research Paper

\title{
Structural and functional insights into nitrosoglutathione reductase from Chlamydomonas reinhardtii
}

\author{
Andrea Tagliani $^{\mathrm{a}, \mathrm{b}, 1,2}$, Jacopo Rossi ${ }^{\mathrm{a}, 1}$, Christophe H. Marchand ${ }^{\mathrm{b}, \mathrm{c}}$, Marcello De Mia ${ }^{\mathrm{b}, 2}$, \\ Daniele Tedesco $^{\mathrm{a}, 2}$, Libero Gurrieri ${ }^{\mathrm{a}}$, Maria Meloni ${ }^{\mathrm{a}}$, Giuseppe Falini ${ }^{\mathrm{d}}$, Paolo Trost ${ }^{\mathrm{a}}$, \\ Stéphane D. Lemaire ${ }^{\text {b, e, }}$, Simona Fermani ${ }^{\text {d,f, }{ }^{* * * *}}$, Mirko Zaffagnini ${ }^{\text {a, }}$ \\ ${ }^{a}$ Department of Pharmacy and Biotechnologies, University of Bologna, I-40126, Bologna, Italy \\ b CNRS, Sorbonne Université, Institut de Biologie Physico-Chimique, UMR8226, F-75005, Paris, France

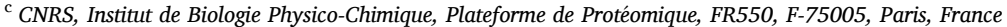 \\ ' Department of Chemistry "G. Ciamician”, University of Bologna, I-40126, Bologna, Italy \\ e Sorbonne Université, CNRS, Institut de Biologie Paris-Seine, Laboratory of Computational and Quantitative Biology, UMR7238, F-75005, Paris, France \\ ${ }^{\mathrm{f}}$ CIRI Health Sciences \& Technologies (HST), University of Bologna, I-40064, Bologna, Italy
}

\section{A R T I C L E I N F O}

\section{Keywords:}

Chlamydomonas

Cysteine

Nitrosoglutathione

Nitrosoglutathione reductase

Redox regulation

Thiol modification

Zinc ions

\begin{abstract}
A B S T R A C T
Protein S-nitrosylation plays a fundamental role in cell signaling and nitrosoglutathione (GSNO) is considered as the main nitrosylating signaling molecule. Enzymatic systems controlling GSNO homeostasis are thus crucial to indirectly control the formation of protein S-nitrosothiols. GSNO reductase (GSNOR) is the key enzyme controlling GSNO levels by catalyzing its degradation in the presence of NADH. Here, we found that protein extracts from the microalga Chlamydomonas reinhardtii catabolize GSNO via two enzymatic systems having specific reliance on NADPH or NADH and different biochemical features. Scoring the Chlamydomonas genome for orthologs of known plant GSNORs, we found two genes encoding for putative and almost identical GSNOR isoenzymes. One of the two, here named CrGSNOR1, was heterologously expressed and purified. Its kinetic properties were determined and the three-dimensional structures of the apo-, $\mathrm{NAD}^{+}$- and $\mathrm{NAD}^{+} / \mathrm{GSNO}^{- \text {forms }}$ were solved. These analyses revealed that CrGSNOR1 has a strict specificity towards GSNO and NADH, and a conserved folding with respect to other plant GSNORs. The catalytic zinc ion, however, showed an unexpected variability of the coordination environment. Furthermore, we evaluated the catalytic response of CrGSNOR1 to thermal denaturation, thiol-modifying agents and oxidative modifications as well as the reactivity and position of accessible cysteines. Despite being a cysteine-rich protein, CrGSNOR1 contains only two solvent-exposed/ reactive cysteines. Oxidizing and nitrosylating treatments have null or limited effects on CrGSNOR1 activity and folding, highlighting a certain resistance of the algal enzyme to redox modifications. The molecular mechanisms and structural features underlying the response to thiol-based modifications are discussed.
\end{abstract}

\section{Introduction}

Nitric oxide $(\bullet \mathrm{NO})$ is a relatively stable free radical widely recognized as a signaling molecule in oxygenic phototrophs where it controls multiple physiological processes (e.g. development, stomatal closure, tolerance to metal toxicity, and adaptive response to abiotic and biotic stresses) [1-8]. The biological actions of $\bullet$ NO are mainly exerted by NO-derived reactive molecules through their ability to react with proteins and trigger the formation of post-translational modifications (PTMs) [9-12]. The major reaction consists in the reversible formation

\footnotetext{
* Corresponding author.

** Corresponding author. CNRS, Sorbonne Université, Institut de Biologie Physico-Chimique, UMR8226, F-75005, Paris, France.

*** Corresponding author. Department of Chemistry "G. Ciamician", University of Bologna, I-40126, Bologna, Italy.

E-mail addresses: stephane.lemaire@ibpc.fr (S.D. Lemaire), simona.fermani@unibo.it (S. Fermani), mirko.zaffagnini3@unibo.it (M. Zaffagnini).

1 These authors contributed equally to this work.

${ }^{2}$ Department of Biosciences, Università degli Studi di Milano, 20133 Milan, Italy (AT); Laboratoire physiologie cellulaire et vegetale, UMR 5168, CEA/CNRS, INRAE, UGA, 38054, Grenoble, France (MDM); Institute for Organic Synthesis and Photoreactivity - National Research Council (ISOF-CNR), 40129 Bologna, Italy (DT).
} 
of a nitrosothiol ( $-\mathrm{SNO}$ ) between a NO moiety and a protein thiol $(-\mathrm{SH})$, in a process named S-nitrosylation [13].

Protein S-nitrosylation has emerged as an important regulatory process in plants and hundreds of proteins have been identified as putative S-nitrosylated targets both in vitro and in vivo [14-22]. However, -NO itself cannot directly react with cysteine thiols, but can readily condense with oxygen leading to the formation of nitrogen dioxide $\left(\bullet \mathrm{NO}_{2}\right)$. Subsequently, $\bullet \mathrm{NO}_{2}$ can react with $\bullet \mathrm{NO}$ to form dinitrogen trioxide $\left(\mathrm{N}_{2} \mathrm{O}_{3}\right)$ that can induce $\mathrm{S}$-nitrosothiol formation by reacting with sulfur atoms of low-molecular weight thiols and protein cysteines [14]. Considering the high intracellular concentration of reduced glutathione (GSH; $\gamma$-Glu-Cys-Gly) (1-5 mM; [23,24]), nitrosoglutathione (GSNO) is suggested to be the most abundant intracellular low-molecular weight S-nitrosothiol $[25,26]$. GSNO is a quite stable NO-carrying molecule that is considered as the major NO reservoir in both plant and animal cells $[26,27]$. In addition, GSNO can donate its NO moiety to protein cysteines through a trans-nitrosylation reaction [13]. Due to GSNO reactivity, its intracellular concentration must be tightly regulated to avoid uncontrolled accumulation of S-nitrosylated proteins that might cause severe perturbations of cell metabolism and signaling. In animals, several enzymes were shown to catabolize GSNO, including thioredoxin (TRX) [28], glutaredoxin (GRX) [29], superoxide dismutase (SOD) [30,31] nitrosoglutathione reductase (GSNOR) [32], human carbonyl reductase 1 (HsCBR1) [33], and the recently described aldo-keto reductase family 1 member A1 (HsAKR1A1) [34]. Unlike TRX, GRX, and SOD, which catalyze the reduction of GSNO yielding GSH and other NO-derived molecules as final products, GSNOR along with HsCBR1 and HsAKR1A1 catalyze the irreversible conversion of GSNO to $\mathrm{N}$-hydroxysulfinamide (GSNHOH), an unstable intermediate that, in the presence of reduced glutathione (GSH), yields oxidized glutathione (GSSG) and hydroxylamine [14,32,35]. For this reason, GSNOR acts as a scavenging system of intracellular GSNO, thereby indirectly influencing the extent of protein S-nitrosylation [36,37]. Consistently, yeast strains, mice, Arabidopsis thaliana and Lotus japonicus plants deficient for GSNOR exhibited increased levels of protein S-nitrosothiols (SNOs) [38-41], while a decrease of SNO levels was observed in plants overexpressing GSNOR [42]. Overall, these data suggest that GSNO positively correlates with S-nitrosylated proteins in vivo, and that GSNOR is an enzymatic scavenging system capable of regulating GSNO levels in different organisms including plants.

GSNOR belongs to the class-III alcohol dehydrogenase family and can be found in most bacteria and all eukaryotes including photosynthetic organisms [32]. This enzyme was originally identified as a glutathione-dependent formaldehyde dehydrogenase and then reclassified as an S-(hydroxymethyl)glutathione (HMGSH) dehydrogenase. Lately, it was found to participate in GSNO catabolism by catalyzing GSNO reduction using NADH as electron donor [32,35,43,44]. In photosynthetic organisms, GSNOR is generally localized in the cytoplasm and encoded by a single gene [45], with few exceptions including poplar, Lotus japonicus and Chlamydomonas reinhardtii which contain two GSNOR nuclear genes [46-48]. Crystal structures show that GSNOR is a homodimeric protein containing two zinc ions per monomer having either a catalytic or a structural role $[35,37,49]$.

Recently, several studies reported that Arabidopsis and poplar GSNOR undergo S-nitrosylation in vivo under conditions of increased endogenous NO levels [48,50]. Moreover, this modification affects GSNOR activity following exposure of Arabidopsis leaf extracts to NO-donors [50] and is controlled by GSH as proven by both in vitro and genetic studies in vivo [51]. The kinetics and structural effects of S-nitrosylation on GSNOR from Arabidopsis have been reported and the nitrosylated cysteine residues identified (Cys10, 271, and 370) [52]. The specific S-nitrosylation of Cys10 triggers AtGSNOR degradation through autophagy under hypoxic conditions [53]. In addition, the redox modification of Cys10 occurs through a trans-nitrosylation reaction involving catalase 3 [54]. Differently, in the leguminosae Lotus japonicus, the two GSNOR isoforms were found to be target of S-nitrosylation without effect on protein catalysis [41]. Plant GSNORs were also found to be inhibited by in vitro treatments with hydrogen peroxide $[41,55,56]$ or after exposure of Arabidopsis and Baccaurea ramiflora plants to the pro-oxidant herbicide paraquat and exogenous hydrogen peroxide, respectively [55,57]. Altogether, these results suggest that most plant GSNORs are responsive to oxidative modifications and transient inhibition of their activity might represent an important mechanism to control GSNO accumulation with an ensuing impact on intracellular GSNO/SNO levels.

In green microalgae such as Chlamydomonas reinhardtii, NO signaling participates in the regulation of nutrients acquisition, photosynthetic efficiency, and other processes including autophagy and cell death [4, 58-62], making its understanding of particular interest for biotechnological purposes. Recently, GSNO reducing activity has been measured in Chlamydomonas reinhardtii extracts following exposure to salt stress [63], but the underlying enzymes along with their functional features are yet to be uncovered.

In this work, we identified the enzymatic systems catalyzing GSNO degradation in C. reinhardtii protein extracts. Genome mining confirmed the presence in Chlamydomonas of two nuclear-encoded genes for putative GSNOR isozymes sharing more than $99 \%$ of sequence identity. Algal GSNOR1 (Cre12.g543400) was cloned and expressed, and its biochemical and structural features determined. Despite being rich in cysteine residues (16 Cys out of 378 total residues), CrGSNOR1 contains only two solvent-exposed/reactive cysteines (i.e. Cys244 and Cys371) and its activity is almost unaffected by in vitro oxidative and nitrosative treatments, suggesting that the algal enzyme is resistant to redox modifications. Nevertheless, crystallographic data clearly show that Cys244 undergoes S-nitrosylation in the presence of the physiological nitrosylating agent GSNO. Based on our findings, we provide functional and structural insights into the response of CrGSNOR1 to cysteine-based modifications.

\section{Material and methods}

\subsection{Chemicals}

Proteomics grade Trypsin Gold was obtained from Promega. Desalting columns (NAP-5 and PD-10) and N-[6-(Biotinamido)hexyl]3'-(2'-pyridyldithio)proprionamide (HPDP-biotin) were purchased from GE Healthcare and Pierce, respectively. All chemicals were obtained from Sigma-Aldrich unless otherwise specified.

\subsection{Synthesis of S-nitrosoglutathione}

GSNO was synthesized from commercial glutathione via an acidcatalyzed nitrosation reaction as previously described in Ref. [64]. Briefly, commercial glutathione (3.065 g) was dissolved in $21 \mathrm{ml}$ of a $476 \mathrm{mM}$ hydrochloric acid solution and kept on ice. Sodium nitrite $(0.691 \mathrm{~g})$ was added at once and the mixture was kept under stirring for $45 \mathrm{~min}$ and protected from light. Then, $10 \mathrm{ml}$ of acetone were added to the red slurry and kept under stirring for an additional $10 \mathrm{~min}$. The slurry was filtered on a glass frit and the precipitate was washed with prechilled distilled water $(4 \times 20 \mathrm{ml})$, acetone $(3 \times 20 \mathrm{ml})$ and diethyl ether $(3 \times 20 \mathrm{ml})$. Water and solvent traces were removed under vacuum for $24 \mathrm{~h}$ and the powder (avg. yield $70 \%$ ) was kept at $-20^{\circ} \mathrm{C}$ in the presence of desiccant. GSNO purity was assessed by ${ }^{1} \mathrm{H}$ NMR and the concentration was determined spectrophotometrically using molar extinction coefficients of $920 \mathrm{M}^{-1} \mathrm{~cm}^{-1}$ and $15.9 \mathrm{M}^{-1} \mathrm{~cm}^{-1}$ at $335 \mathrm{~nm}$ and $545 \mathrm{~nm}$, respectively.

\subsection{Cell culture, growth conditions and protein extraction}

Conditions for Chlamydomonas cultures and protein extraction were adapted from Ref. [17]. Briefly, the Chlamydomonas D66 cell-wall-less strain (CC-4425 cw nit2-203mt+ strain) was grown in Tris-acetate 
phosphate (TAP) medium under continuous light $\left(80 \mu \mathrm{E} \mathrm{m}^{-2} \mathrm{~s}^{-1}\right)$ at

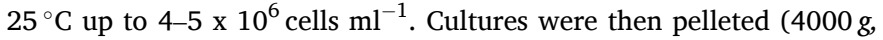
$5 \mathrm{~min}$ ) and resuspended in $50 \mathrm{mM}$ Tris- $\mathrm{HCl} \mathrm{pH}$ 7.9. Total soluble proteins were then extracted by three cycles of freeze/thaw in liquid nitrogen. The protein extract was then clarified by centrifugation $(15000 \mathrm{~g}$ for $10 \mathrm{~min}$ at $4{ }^{\circ} \mathrm{C}$ ) and protein concentration was assessed by BCA Protein Assay using bovine serum albumin (BSA) as standard.

\section{4. $N A D(P) H$-dependent GSNO reductase activity in protein extracts}

The NAD(P)H-dependent GSNO reductase activity was measured adding variable amounts of freshly prepared protein extracts $(0.125-1 \mathrm{mg})$ in a reaction mixture $(1 \mathrm{ml})$ containing $50 \mathrm{mM}$ Tris- $\mathrm{HCl}$ $\mathrm{pH} 7.9,0.2 \mathrm{mM} \mathrm{NAD}(\mathrm{P}) \mathrm{H}$ and $0.4 \mathrm{mM}$ GSNO. The activity was determined spectrophotometrically following NAD(P)H oxidation at $340 \mathrm{~nm}$ using a molar extinction coefficient of $7060 \mathrm{M}^{-1} \mathrm{~cm}^{-1}$ at $340 \mathrm{~nm}$, which includes both NAD(P)H and GSNO absorbance. The linear rate of the reaction was corrected with a reference rate without GSNO. Activity measurements were performed at least in three biological triplicates using $1 \mathrm{~cm}$ path length cuvettes.

\subsection{Thiol-modifying treatments and thermal stability of protein extracts}

Freshly prepared protein extracts $(500 \mu \mathrm{g})$ were incubated at $25^{\circ} \mathrm{C}$ in $50 \mathrm{mM}$ Tris- $\mathrm{HCl}, \mathrm{pH} 7.9$ in the presence of $1 \mathrm{mM} \mathrm{N}$-ethylmaleimide (NEM) or $1 \mathrm{mM}$ and methyl methanethiosulfonate (MMTS). At the indicated times, aliquots $(10-50 \mu \mathrm{l})$ were withdrawn to carry out activity measurements as described above. Control experiments were performed by incubating protein extracts in the presence of $2 \mathrm{mM}$ reduced DTT. Thermal stability was carried out by incubating protein extracts $(500 \mu \mathrm{g})$ for $5 \mathrm{~min}$ from $40^{\circ} \mathrm{C}$ up to $80^{\circ} \mathrm{C}$ with $10^{\circ} \mathrm{C}$ increments. Subsequently, protein samples were centrifuged $(15000 \mathrm{~g}$ for $5 \mathrm{~min}$ at $4{ }^{\circ} \mathrm{C}$ ) to remove precipitated proteins, and the NAD(P)H-dependent activities were monitored as described above. Control experiments were performed by incubating protein extracts at $25^{\circ} \mathrm{C}$ following the centrifugation step.

\subsection{Cloning, expression and purification of CrGSNOR1}

The coding sequence for CrGSNOR1 (locus Cre12.g543400) was amplified by standard RT-PCR on Chlamydomonas total RNA extracts using a forward primer introducing an NdeI restriction site (in bold) at the start codon: 5' $^{\prime}$ CATGCCCATATGTCGGAAACTGCAGGCAAG- ${ }^{\prime}$ and a reverse primer introducing a BamHI restriction site (in bold) downstream of the stop codon: 5'-CATGCCGGATCCCTAGAACGTCAGCACACA-3'. CrGSNOR1 was cloned in a modified pET-3c vector [65] containing additional codons upstream of the NdeI site to express a His-tagged protein with seven $\mathrm{N}$-terminal histidines. The sequence was checked by sequencing. Recombinant CrGSNOR1 was produced using the pET-3c-His/BL21 expression system. Bacteria were grown in LB medium supplemented with $100 \mu \mathrm{g} \mathrm{m} l^{-1}$ ampicillin at $37^{\circ} \mathrm{C}$ and the production was induced with $100 \mu \mathrm{M}$ isopropyl $\beta$-D-1-thiogalactopyranoside overnight at $30^{\circ} \mathrm{C}$. Cells were then harvested by centrifugation (5000 $\mathrm{g}$ for $10 \mathrm{~min}$ ) and resuspended in $50 \mathrm{mM}$ Tris-HCl pH 7.9. Cell lysis was performed using a French press $\left(6.9 \times 10^{7} \mathrm{~Pa}\right)$ and cell debris were removed by centrifugation ( $5000 \mathrm{~g}$ for $15 \mathrm{~min}$ ). To avoid nucleic acids contamination, the sample was incubated with RNase $\left(0.01 \mathrm{mg} \mathrm{ml}^{-1}\right)$ and DNAse $\left(0.04 \mathrm{U} \mathrm{ml}^{-1}\right)$ for $30 \mathrm{~min}$ at RT under mild shaking. The supernatant was then centrifuged at $15000 \mathrm{~g}$ for $30 \mathrm{~min}$ and applied onto a $\mathrm{Ni}^{2+}$ Hitrap chelating resin (HIS-Select Nickel Affinity Gel; Sigma-Aldrich) equilibrated with $30 \mathrm{mM}$ Tris- $\mathrm{HCl} \mathrm{pH} 7.9$ containing $500 \mathrm{mM} \mathrm{NaCl}$ (TN buffer) and $5 \mathrm{mM}$ imidazole. The recombinant protein was purified according to the manufacturer's instructions. The molecular mass and purity of the protein were analyzed by SDS-PAGE after desalting with PD-10 columns equilibrated with $30 \mathrm{mM}$ Tris- $\mathrm{HCl}$ pH 7.9. The concentration of CrGSNOR1 was determined spectrophotometrically using a molar extinction coefficient at $280 \mathrm{~nm}$ $\left(\varepsilon_{280}\right)$ of $40910 \mathrm{M}^{-1} \mathrm{~cm}^{-1}$. The resulting homogeneous protein solutions were stored at $-20^{\circ} \mathrm{C}$.

\subsection{Enzymatic assays for GSNOR activities}

The catalytic activity of purified CrGSNOR1 was measured spectrophotometrically as described above. The reaction was initiated by the addition of CrGSNOR1 at a final concentration ranging from 5 to $50 \mathrm{nM}$. The NADH-dependent activity of CrGSNOR1 was also assayed in the presence of oxidized glutathione $(0.4$ or $4 \mathrm{mM})$ or $0.2 \mathrm{mM} \mathrm{NADPH}$ instead of GSNO or NADH, respectively. S-(hydroxymethyl)glutathione (HMGSH) oxidation by CrGSNOR1 was assessed following the procedure described in Refs. [66]. Briefly, the activity was determined spectrophotometrically following $\mathrm{NAD}^{+}$reduction in a reaction mixture containing $50 \mathrm{mM}$ Tris- $\mathrm{HCl} \mathrm{pH}$ 7.9, $0.2 \mathrm{mM} \mathrm{NAD}^{+}$and $1 \mathrm{mM} \mathrm{HMGSH}$. The activity was measured as the increase in absorbance at $340 \mathrm{~nm}$ using a $\varepsilon_{340}$ of $6220 \mathrm{M}^{-1} \mathrm{~cm}^{-1}$.

\subsection{Kinetic properties of CrGSNOR1}

Steady-state kinetic analysis was accomplished by varying the concentrations of NADH $(0.005-0.2 \mathrm{mM})$ at a fixed GSNO concentration $(0.4 \mathrm{mM})$ and the concentration of GSNO $(0.0125-0.4 \mathrm{mM})$ at a fixed concentration of NADH $(0.2 \mathrm{mM})$. The reaction was started by adding $25 \mathrm{nM}$ CrGSNOR1. Three independent experiments were performed at each substrate concentration and apparent kinetic parameters $\left(K_{\mathrm{m}}^{\prime}\right.$ and $k_{\text {cat }}^{\prime}$ ) were calculated by nonlinear regression using the MichaelisMenten equation with the program CoStat (CoHort Software, Monterey, CA).

\subsection{Thermal stability of purified CrGSNOR1}

The thermostability of purified CrGSNOR1 $(5 \mu \mathrm{M})$ was assessed by measuring protein activity after $30 \mathrm{~min}$ incubation of the enzyme at temperatures ranging from $25^{\circ} \mathrm{C}$ up to $75^{\circ} \mathrm{C}$ with $5^{\circ} \mathrm{C}$ increments. Kinetics of CrGSNOR1 aggregation were assessed by measuring the increase of turbidity at $405 \mathrm{~nm}$ CrGSNOR1 samples were incubated in $30 \mathrm{mM}$ Tris- $\mathrm{HCl}, \mathrm{pH} 7.9$ at the indicated temperatures in a low-proteinbinding 96-well plate. Samples were monitored at interval times and turbidity was measured using a plate reader (Victor3 Multilabeling Counter; PerkinElmer).

\subsection{Thiol-modifying treatments of CrGSNOR1}

Treatments were performed at room temperature by incubating purified CrGSNOR1 $(5 \mu \mathrm{M})$ in $50 \mathrm{mM}$ Tris-HCl, pH 7.9 in the presence of NEM and MMTS at $1 \mathrm{mM}$. After $30 \mathrm{~min}$ incubation, aliquots were withdrawn to assay GSNOR activity as described above.

\subsection{Alkylation of CrGSNOR1 by maleimide-based reagents}

Recombinant CrGSNOR1 $(10 \mu \mathrm{M})$ was incubated in $30 \mathrm{mM}$ Tris-HCl, $\mathrm{pH} 7.9$ at room temperature in the presence of either $1 \mathrm{mM}$ N-ethyl maleimide (100 mM stock solution prepared in water) or $1 \mathrm{mM}$ Biotinmaleimide ( $50 \mathrm{mM}$ stock solution prepared in DMSO). At indicated time points $(20,30,60,90 \mathrm{~min})$ DTT $(10 \mathrm{mM})$ was added to quench maleimide derivatives.

\subsection{In-solution trypsin digestion}

Alkylated CrGSNOR1 $(100 \mu \mathrm{l})$ was immediately desalted by gel filtration using NAP-5 columns equilibrated in water as recommended by the supplier. Then, the desalted protein samples (ca. $500 \mu \mathrm{l}$ ) were concentrated using a SpeedVac concentrator. CrGSNOR1 concentration was determined spectrophotometrically before a $3 \mathrm{~h}$ digestion step with 
trypsin (1:20 (w/w) enzyme:substrate ratio) in $25 \mathrm{mM}$ ammonium bicarbonate (AMBIC). Trypsin digestion was stopped either by heating at $95^{\circ} \mathrm{C}$ for $3 \mathrm{~min}$ or by ultrafiltration using $0.5 \mathrm{ml}$ Amicon Ultra centrifugal devices (20 kDa MWCO, Millipore). A five microliters aliquot was kept for MALDI-TOF MS analysis and the rest was used for the enrichment of biotinylated peptides by affinity chromatography.

\subsection{Affinity purification of cysteinyl peptides alkylated by biotin- maleimide}

Affinity purification was performed as previously described in Ref. [67] with slight modifications. Briefly, around $75 \mu \mathrm{l}$ of monomeric avidin agarose (Pierce) were packed into a gel-loading tip and further equilibrated with $200 \mathrm{mM} \mathrm{NaCl}$ in $25 \mathrm{mM}$ AMBIC (loading buffer). Peptide mixture was supplemented with $200 \mathrm{mM} \mathrm{NaCl}$ before loading by centrifugation $\left(20^{\circ} \mathrm{C}, 1 \mathrm{~min}, 40 \mathrm{~g}\right)$. The flow through was kept and reloaded three times. Then, avidin agarose was extensively washed by centrifugation with $4 \times 150 \mu$ lof loading buffer and $4 \times 150 \mu \mathrm{l}$ of $25 \mathrm{mM}$ AMBIC in 20\% methanol. Peptides retained onto the packed monomeric avidin column were eluted using $150 \mu \mathrm{l}$ of $0.4 \%$ trifluoroacetic acid (TFA) in $30 \%$ acetonitrile (ACN) and were directly analyzed by MALDI-TOF without further treatment.

\subsection{MALDI-TOF MS analyses}

Mass spectrometry experiments were performed as previously described in Ref. $[68,69]$. Briefly, for analysis of intact proteins by mass spectrometry, $1 \mu$ l of protein sample (previously quenched with DTT as described above) was taken and mixed with $2 \mu$ of a saturated solution of sinapinic acid in 30/0.3 ACN/TFA. Two microliters of this premix were spotted onto the sample plate and allowed to dry under a gentle air stream at room temperature. Spectra were acquired in positive linear mode on an Axima Performance MALDI-TOF/TOF mass spectrometer (Shimadzu-Kratos, Manchester, UK) with a pulse extraction fixed at 50000. Mass determination was performed after external calibration using mono-charged and dimer ions of yeast enolase.

\subsection{Treatments of CrGSNOR1 with oxidizing or nitrosylating agents}

Oxidizing and nitrosylating treatments were performed at $25^{\circ} \mathrm{C}$ by incubating purified CrGSNOR1 $(5 \mu \mathrm{M})$ in $50 \mathrm{mM}$ Tris- $\mathrm{HCl}, \mathrm{pH} 7.9$ in the presence of $1 \mathrm{mM}$ hydrogen peroxide $\left(\mathrm{H}_{2} \mathrm{O}_{2}\right)$, or $1 \mathrm{mM}$ diamide (TMAD), or $2 \mathrm{mM} \mathrm{GSNO}$, or SNAP (0.2 and $2 \mathrm{mM}$ ). After $30 \mathrm{~min}$ incubation, an aliquot was withdrawn, and enzyme activity was assayed as described above. Reactivation of SNAP-treated CrGSNOR1 was carried out after $20 \mathrm{~min}$ incubation in the presence of $10 \mathrm{mM}$ DTT.

\subsection{Titration of free thiol groups}

The number of free thiols in CrGSNOR1 protein was determined spectrophotometrically under non-denaturing conditions with $5,5^{\prime}$ dithiobis-2-nitrobenzoic acid (DTNB) [18,70]. Briefly, $5 \mu \mathrm{M}$ protein was incubated with $200 \mu \mathrm{M}$ DTNB in $100 \mathrm{mM}$ Tris-HCl, pH 7.9. After $30 \mathrm{~min}$ at room temperature, the absorbance at $412 \mathrm{~nm}$ was determined. A molar extinction coefficient of $14,150 \mathrm{M}^{-1} \mathrm{~cm}^{-1}$ was used to calculate the number of titrated thiol groups. The same procedure was also applied to CrGSNOR1 treated with $\mathrm{H}_{2} \mathrm{O}_{2}$ or GSNO. Before reacting with DTNB, the protein samples $(10 \mu \mathrm{M})$ were incubated in the presence of $1 \mathrm{mM} \mathrm{H}_{2} \mathrm{O}_{2}$ or $2 \mathrm{mM} \mathrm{GSNO}$ and then desalted in $100 \mathrm{mM}$ Tris- $\mathrm{HCl}(\mathrm{pH}$ 7.9) using NAP-5 columns.

\subsection{Biotin switch technique}

Purified CrGSNOR1 was incubated in TEN buffer ( $30 \mathrm{mM}$ Tris-HCl pH 7.9, EDTA $1 \mathrm{mM}, \mathrm{NaCl} 100 \mathrm{mM}$ ) in the presence of $2 \mathrm{mM}$ GSNO or $2 \mathrm{mM}$ SNAP for $30 \mathrm{~min}$ in the dark at $25^{\circ} \mathrm{C}$. The extent of protein nitrosylation was assessed by following the procedure described in Ref. [22]. After nitrosylation treatments, proteins $\left(\sim 1 \mathrm{mg} \mathrm{ml}^{-1}\right)$ were precipitated with two volumes of $80 \%$ cold acetone at $-20^{\circ} \mathrm{C}$ during $20 \mathrm{~min}$ and pelleted by centrifugation at $4{ }^{\circ} \mathrm{C}$ for $10 \mathrm{~min}$ at $15,000 \mathrm{~g}$. The pellet was resuspended in TENS buffer ( $30 \mathrm{mM}$ Tris- $\mathrm{HCl} \mathrm{pH} 7.9,1 \mathrm{mM}$ EDTA, $100 \mathrm{mM} \mathrm{NaCl}$ and $1 \%$ SDS) supplemented with a cocktail of alkylating reagents ( $10 \mathrm{mM}$ iodoacetamide, $10 \mathrm{mM} \mathrm{N}$-ethylmaleimide), to allow blocking of free thiols. After $30 \mathrm{~min}$ incubation at $25^{\circ} \mathrm{C}$ under shaking, the samples were acetone precipitated, as described above, to remove unreacted alkylating reagents. After resuspension in TENS buffer, proteins were incubated in the presence of $40 \mathrm{mM}$ ascorbate and $1 \mathrm{mM}$ N-[6-(Biotinamido)hexyl]-3 '-(2 '-pyridyldithio)propionamide (HPDP-biotin) for $30 \mathrm{~min}$. This step allows reduction of S-nitrosylated cysteines and their derivatization with biotin. Proteins were then acetone precipitated to remove unreacted labelling compounds, pelleted by centrifugation as above and resuspended in TENS buffer. All steps were performed in the dark. After the final precipitation, proteins were quantified using the bicinchoninic acid assay, separated by non-reducing SDS-PAGE and transferred onto nitrocellulose membranes. Protein loading and transfer were assessed by Ponceau staining of the membrane. Proteins were then analyzed by western blotting using a primary anti-biotin antibody (1:5000 dilution; Sigma-Aldrich) and an anti-mouse secondary antibody coupled to peroxidase (1:10,000 dilution; Sigma-Aldrich). Signals were visualized by enhanced chemiluminescence as described previously [71]. All BST assays included a negative control where ascorbate was omitted to prevent reduction of S-nitrosothiols and subsequent biotinylation.

\subsection{Quaternary structure determination}

Gel filtration analysis was performed on a Superdex 200 HR10/ 300 GL column (GE Healthcare) connected to an ÅTA Purifier system (GE Healthcare), previously calibrated with standard proteins, namely ferritin (440 kDa), aldolase (158 kDa), ovalbumin (43 kDa), and chymotrypsinogen A (25 kDa), as described in Ref. [65]. The column was equilibrated with $50 \mathrm{mM}$ Tris- $\mathrm{HCl}, \mathrm{pH} 7.5$ and $150 \mathrm{mM} \mathrm{KCl}$. The loading volume of CrGSNOR1 samples was $0.25 \mathrm{ml}$ at a concentration above $1 \mathrm{mg} \mathrm{ml}^{-1}$ and fractions of $0.5 \mathrm{ml}$ were collected at a flow rate of $0.5 \mathrm{ml} \mathrm{min}^{-1}$. DLS measurements were performed employing a Malvern Nano ZS instrument equipped with a $633 \mathrm{~nm}$ laser diode [72]. Samples consisting of CrGSNOR1 $(5-50 \mu \mathrm{M})$ in $30 \mathrm{mM}$ Tris-HCl, pH 7.9 were introduced in disposable polystyrene cuvettes $(100 \mu \mathrm{l})$ of $1 \mathrm{~cm}$ optical path length. The width of DLS hydrodynamic radius distribution is indicated by the polydispersion index. In the case of a monomodal distribution (Gaussian) calculated by means of cumulant analysis, PdI = $\left(\sigma / Z_{\text {avg }}\right)^{2}$, where $\sigma$ is the width of the distribution and $Z_{\text {avg }}$ is the average radius of the protein population. The reported hydrodynamic radii $\left(R_{h}\right)$ have been averaged from the values obtained from five measurements, each one being composed of ten runs of $10 \mathrm{~s}$.

\subsection{Crystallization and data collection}

The apo-, $\mathrm{NAD}^{+}$- and $\mathrm{NAD}^{+} / \mathrm{GSNO}-\mathrm{CrGSNOR} 1$ were crystallized using the hanging drop vapor diffusion method at $20^{\circ} \mathrm{C}$. The drop was obtained by mixing $2 \mu \mathrm{lof} 5 \mathrm{mg} \mathrm{m}^{-1}$ protein solution in $30 \mathrm{mM}$ Tris$\mathrm{HCl}, \mathrm{pH} 7.9,1 \mathrm{mM}$ EDTA plus $1 \mathrm{mM} \mathrm{NAD}^{+}$for $\mathrm{NAD}^{+}$-enzyme or plus $1 \mathrm{mM} \mathrm{NAD}^{+}$and $2 \mathrm{mM}$ GSNO for $\mathrm{NAD}^{+} /$GSNO-enzyme, and an equal volume of a reservoir solution containing $0.1 \mathrm{M}$ Tris- $\mathrm{HCl} \mathrm{pH} \mathrm{8.5,} 0.1 \mathrm{M}$ $\mathrm{MgCl}_{2}$ or $\mathrm{Mg}\left(\mathrm{CH}_{3} \mathrm{CO}_{2}\right)_{2}$, and $12-15 \%$ w/v PEG $20 \mathrm{~K}$ or $12 \% \mathrm{w} / \mathrm{v}$ PEG $8 \mathrm{~K}$ as precipitant. Crystals with a rod-like morphology appeared after about 10 days. The crystals were fished, briefly soaked in a cryo-solution containing the reservoir components plus $20 \% \mathrm{v} / \mathrm{v}$ PEG 400, and then frozen in liquid nitrogen. Diffraction data were collected at $100 \mathrm{~K}$ using the synchrotron radiation of the beamline ID23-1 at ESRF (Grenoble, France) for apo-CrGSNOR1 and of the XRD1 beamline at Elettra (Trieste, Italy) for $\mathrm{NAD}^{+}$- and $\mathrm{NAD}^{+} / \mathrm{GSNO}-\mathrm{CrGSNOR} 1$. Data collections were 
performed with a wavelength of $1.0 \AA$ for all crystals, an oscillation angle $(\Delta \phi)$ of $0.1^{\circ}$ and a sample-to-detector distance (d) of $385.62 \mathrm{~mm}$ (Pilatus 6 M) for the apo-enzyme, a $\Delta \phi=0.3^{\circ}$ and $\mathrm{d}=260.00 \mathrm{~mm}$ (Pilatus $2 \mathrm{M}$ ) for the $\mathrm{NAD}^{+}$-enzyme and a $\Delta \phi=0.5^{\circ}$ and $\mathrm{d}=350.00 \mathrm{~mm}$ (Pilatus $2 \mathrm{M}$ ) for the $\mathrm{NAD}^{+} / \mathrm{GSNO}$-enzyme. The images were indexed with XDS [73] and scaled with AIMLESS [74] from the CCP4 package. The unit cell parameters and the data collection statistics are reported in Supplemental Table 1.

\subsection{Structure solution and refinement}

Apo-CrGSNOR1 structure was solved by molecular replacement with the program MOLREP [75] using the coordinates of apo-GSNOR from tomato as search model (PDB code 4DLA; [35]). Three dimers were placed in the asymmetric unit consistently with the calculated Matthews coefficient [76] equal to $2.4 \AA^{3} \mathrm{Da}^{-1}$ for six molecules in the asymmetric unit and corresponding to a solvent content of $48 \%$. The refinement was performed with REFMAC 5.8.0135 77 selecting 5\% of reflections for $\mathrm{R}_{\text {free, }}$, and the manual rebuilding with Coot [78]. Water molecules were automatically added and, after a visual inspection, confirmed in the model only if contoured at $1.0 \sigma$ on the $\left(2 F_{\mathrm{o}}-F_{\mathrm{c}}\right)$ electron density map and they fell into an appropriate hydrogen-bonding environment. Several PEG molecules, chloride and magnesium ions coming from the crystallization solution were identified and added to the model. The last refinement cycle was performed with PHENIX [79].

Since $\mathrm{NAD}^{+}$- and $\mathrm{NAD}^{+} / \mathrm{GSNO}-\mathrm{CrGSNOR} 1$ crystals were isomorphous with the apo-form, the final coordinates of apo-CrGSNOR1 were directly used for refinement providing $R$ and $R_{\text {free }}$ values of 0.23 and 0.28 for $\mathrm{NAD}^{+}$structure and 0.19 and 0.27 for $\mathrm{NAD}^{+} / \mathrm{GSNO}$ structure, respectively. The calculated $2 F_{\mathrm{o}}-F_{\mathrm{c}}$ and $F_{\mathrm{o}}-F_{\mathrm{c}}$ electron density maps revealed a clear density for $\mathrm{NAD}^{+}$in each monomer that was added to the structural model. Moreover, an extended positive density was observed in all protein chains close to the thiol group of Cys244 and it was attributed to a nitrosothiol group built into the structural model.

The refinement of the $\mathrm{NAD}^{+}$- and $\mathrm{NAD}^{+} / \mathrm{GSNO}$-structures was performed as described for the apo-form. Refinement statistics are reported in Supplemental Table 1. The stereo-chemical quality of the models was checked with Molprobity [80]. Molecular graphics images were generated using PyMOL (The PyMOL Molecular Graphics System, Schrödinger, LLC) and Ligplot [81].

\subsection{Secondary structure analysis}

The secondary structure of CrGSNOR1 was investigated by means of circular dichroism (CD) spectroscopy. Samples of CrGSNOR1 (10.7 $\mu \mathrm{M})$ were prepared in $30 \mathrm{mM}$ Tris- $\mathrm{HCl}, \mathrm{pH} 7.9$ and quantified by spectrophotometric analysis at $280 \mathrm{~nm}$ in a $1 \mathrm{~cm}$ cell [82]. Oxidized CrGNSOR1 samples were obtained by treatment with either $\mathrm{H}_{2} \mathrm{O}_{2}(1 \mathrm{mM})$ or GSNO $(2 \mathrm{mM})$ and incubation for $30 \mathrm{~min}$. The far-UV CD spectra $(260-190 \mathrm{~nm})$ of all samples were measured at room temperature on a J-810 spectropolarimeter (Jasco, Japan), using a QS-quartz cylindrical cell with $0.2 \mathrm{~mm}$ optical pathlength (Hellma Analytics, Germany), a $1 \mathrm{~nm}$ spectral bandwidth, a $20 \mathrm{~nm} / \mathrm{min}$ scanning speed, a $4 \mathrm{~s}$ data integration time, a $0.2 \mathrm{~nm}$ data interval and an accumulation cycle of 6 scans. The resulting $\mathrm{CD}$ spectra were corrected by subtracting the spectral contribution of solvent and eventual oxidizing agents, then converted to molar units per residue ( $\Delta \varepsilon$ res, in $\mathrm{M}^{-1} \mathrm{~cm}^{-1}$ ). The estimation of the secondary structure from the $\mathrm{CD}$ spectra of native and $\mathrm{H}_{2} \mathrm{O}_{2}$-treated CrGSNOR1 samples was performed using the CONTIN-LL algorithm [83] and the 48-protein reference set 7 [84] available on the DichroWeb web server (http ://dichroweb.cryst.bbk.ac.uk/) [85]. The cut-off of measurements on GSNO-treated CrGSNOR1 had to be shifted to $200 \mathrm{~nm}$ due to the high UV absorption of GSNO. As a consequence, the estimation of the secondary structure could not be performed using the same method because the required wavelength interval $(240-190 \mathrm{~nm})$ exceeded the experimental spectral range available.

\subsection{Accession numbers}

Atomic coordinates and structure factors have been deposited in the Protein Data Bank (www.wwpdb.org) under PDB ID codes 7AAS, 7AAU and 7AV7 for apo, $\mathrm{NAD}^{+}$- and $\mathrm{NAD}^{+} /$GSNO-CrGSNOR1, respectively.

\section{Results}

3.1. Distinct NADPH- and NADH-dependent enzymatic systems catalyze GSNO reduction in C. reinhardtii

To determine whether $C$. reinhardtii contains enzymatic systems able to catabolize GSNO, we examined GSNO reduction in the presence of $\mathrm{NADPH}$ or NADH by monitoring the decrease in absorbance at $340 \mathrm{~nm}$. Chlamydomonas protein extracts were found to catalyze GSNO reduction using both cofactors and the relative activities correlated with protein content (Fig. 1A and B). The NADPH-dependent specific activity $\left(75.9 \pm 10.0 \mathrm{nmol} \mathrm{min}^{-1} \mathrm{mg}^{-1}\right)$ was around two-fold higher compared to that measured in the presence of NADH $\left(32.9 \pm 2.3 \mathrm{nmol} \mathrm{min}^{-1}\right.$ $\mathrm{mg}^{-1}$ ). To investigate whether the NADPH- and NADH-dependent activities are due to different enzymatic systems, we sought to find conditions that allowed uncoupling them. We first compared the thermal stability of the two enzymatic activities as it is well established that enzymes can exhibit very different sensitivity to temperature [86]. After incubation of protein extracts at varying temperatures ranging from $25^{\circ} \mathrm{C}$ to $80^{\circ} \mathrm{C}$, we measured GSNO degradation in the presence of both cofactors. The NADPH-dependent activity was resistant to temperature up to $70^{\circ} \mathrm{C}$ and strong inactivation was only achieved at $80^{\circ} \mathrm{C}$ (Fig. 1C). By contrast, NADH-dependent GSNO degradation exhibited a much higher sensitivity to heating, retaining $85 \%, 20 \%$ and $5 \%$ residual activity at $50^{\circ} \mathrm{C}, 60^{\circ} \mathrm{C}$ and $70^{\circ} \mathrm{C}$, respectively (Fig. 1D).

Further analyses were conducted aimed at investigating the response of NAD(P)H-dependent GSNO degrading activities to thiol-modifying agents such as N-ethylmaleimide (NEM) and methyl methanethiosulfonate (MMTS). These two compounds share a strong reactivity towards cysteine residues, but while NEM induces irreversible alkylation, MMTS reacts with sulfhydryl groups (-SH) forming a mixed disulfide (-S-S- $\mathrm{CH}_{3}$, dithiomethane). In addition, NEM exclusively reacts with accessible cysteine residues while MMTS can also react with metal-coordinating cysteine thiols [87]. The exposure of protein extracts to NEM led to a strong and rapid inactivation of the NADPH-dependent activity whereas no effect was observed when we assayed GSNO reduction in the presence of NADH (Fig. 1E and F). By contrast, MMTS had no significant effect on the NADPH-dependent activity whereas it induced a partial decrease of NADH-dependent activity, retaining $\sim 60 \%$ residual activity after $30 \mathrm{~min}$ incubation (Fig. $1 \mathrm{E}$ and $\mathrm{F}$ ).

Based on these findings, we can sustain that Chlamydomonas protein extracts contain at least two distinct GSNO-reducing enzymatic systems exhibiting specific cofactor dependence and different sensitivities to thermal denaturation and cysteine-modifying molecules.

\subsection{The Chlamydomonas genome contains two genes encoding nearly identical GSNOR isoforms}

Since plant and non-plant GSNORs are known to specifically use $\mathrm{NADH}$ as electron donor, we sought to establish that the algal enzymatic system catalyzing NADH-dependent GSNO degradation could be ascribed to a GSNOR ortholog. Blast searches using GSNOR sequences from diverse sources revealed the presence of two GSNOR genes in the Chlamydomonas nuclear genome (v5.5). The two genes were annotated as formaldehyde dehydrogenases and we name them here GSNOR1 (Cre12.g543400) and GSNOR2 (Cre12.g543350). The two genes are most probably the result of a recent duplication, as they are adjacent and code for almost identical proteins ( $\sim 99 \%$ sequence identity, Supplemental Fig. 1). Multiple sequence alignments revealed that Chlamydomonas GSNORs (CrGSNORs) show 70\% and 65\% sequence identity with 
A

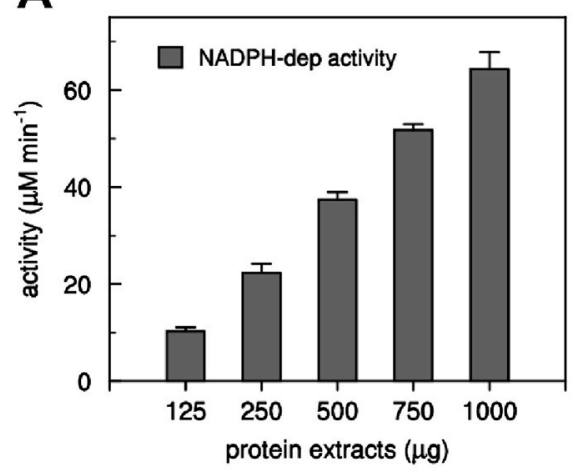

B

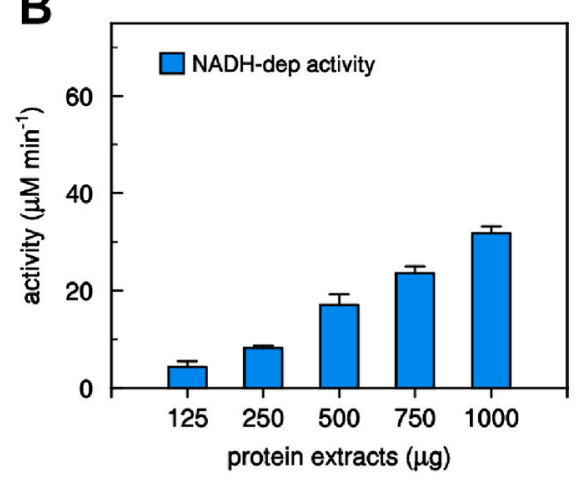

C

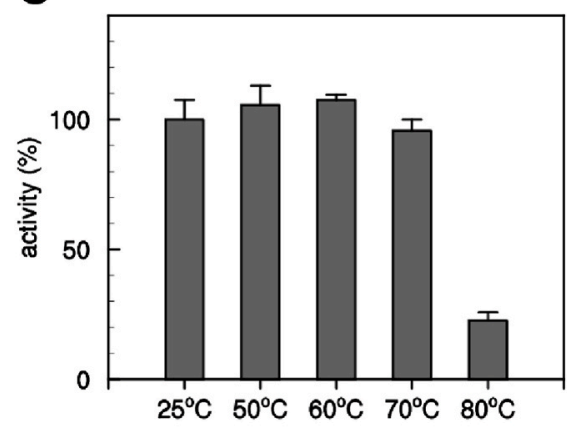

D

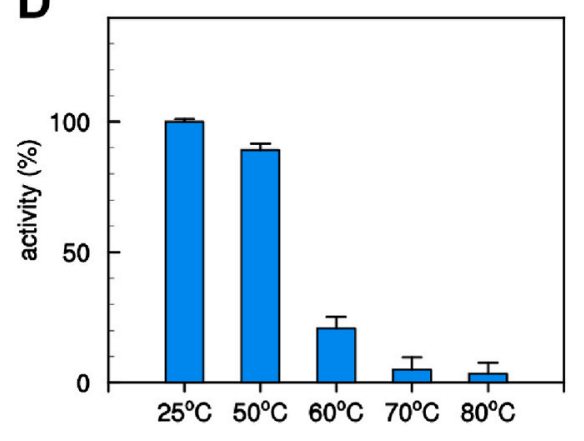

E

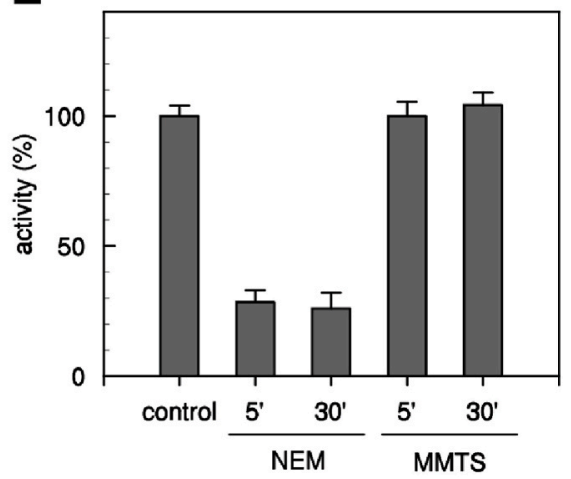

$\mathbf{F}$

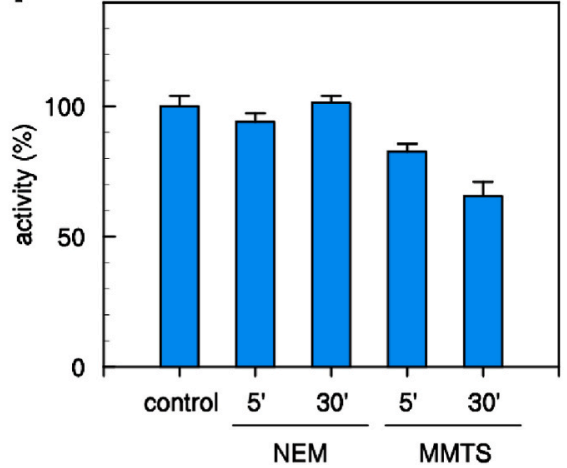

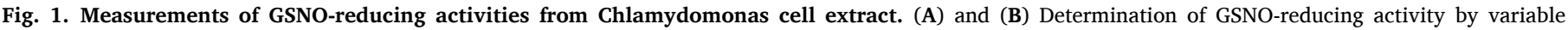

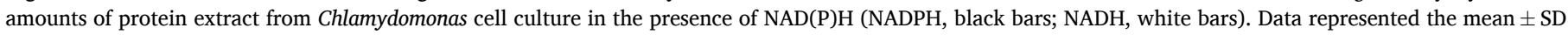

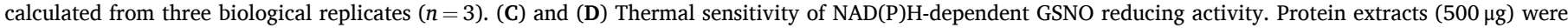

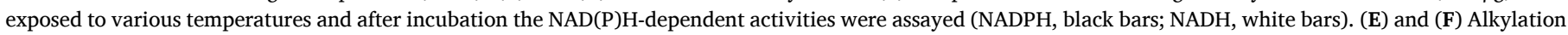

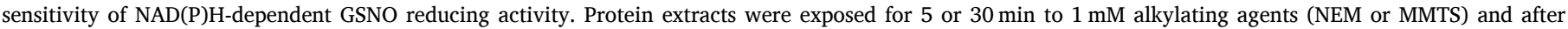

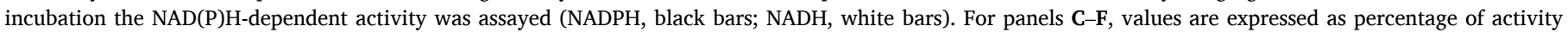
measured under control conditions (see Material and Methods) and are represented as mean percentage \pm SD of three biological replicates $(n=3$ ).

structurally solved GSNORs from land plants (i.e. Arabidopsis thaliana and Solanum lycopersicum) and human cells, respectively (Fig. 2). Comparison of CrGSNOR sequences with GSNORs from different plant and non-plant species showed a similar amino acid conservation ranging from $54 \%$ to $72 \%$ sequence identity apart from GSNOR from the green alga Volvox carteri (90\% identity) (Supplemental Fig. 2). The residues involved in the coordination of both catalytic and structural zinc ions are fully conserved, and this also applies to residues participating in the stabilization of the cofactor $\mathrm{NAD}(\mathrm{H})$ (Fig. 2). Based on the high sequence identity among analyzed GSNORs, we can hypothesize that algal GSNORs represent the enzymes responsible for the NADH-dependent GSNO reduction detected in Chlamydomonas protein extracts. To confirm this hypothesis, we investigated the structural and functional properties of CrGSNORs by focusing our attention on isoform 1 (CrGSNOR1).

\subsection{CrGSNOR1 is a homodimeric protein displaying a conserved folding}

To gain insight into the structural features of CrGSNOR1, we heterologously expressed the enzyme in $E$. coli as a 386 amino acids polypeptide (full-length protein plus the MHHHHHHH peptide at the $\mathrm{N}$ terminus) and purified it to homogeneity by $\mathrm{Ni}^{2+}$ affinity chromatography. The purified protein migrated as a single band of $\sim 40 \mathrm{kDa}$ on SDS-PAGE under both reducing and non-reducing conditions (Supplemental Fig. 3A), and MALDI-TOF mass spectrometry confirmed that recombinant CrGSNOR1 had the expected molecular mass of 41500.6 Da (Supplemental Fig. 3B). Gel filtration and DLS analyses were conducted to determine the oligomerization state of CrGSNOR1. The enzyme eluted as a single symmetric peak with an apparent molecular mass of $96.4 \pm 6.1 \mathrm{kDa}$ and the elution profile at $280 \mathrm{~nm}$ perfectly correlated with GSNOR activity (Supplemental Fig. 3C). These results clearly indicate that CrGSNOR1 protein is a non-covalent homodimer as further confirmed by DLS analysis that reported a hydrodynamic radius of $4.14 \pm 0.2 \mathrm{~nm}$, corresponding to an apparent molecular mass of $93.6 \pm 4.3 \mathrm{kDa}$.

The dimeric fold was chiefly established by solving the crystal structure of CrGSNOR1 under both apo- and holo-form $\left(\mathrm{NAD}^{+}\right.$. CrGSNOR1) at a resolution of 1.8 and $2.3 \AA$, respectively (Fig. 3A and B). The apo- and holo-enzymes showed an identical crystalline packing with three dimers in the asymmetric unit and a similar overall structure with root mean square deviation (rmsd) values ranging from 0.20 to $0.86 \AA$ and from 0.33 to $0.97 \AA$ for monomers and dimers superimposition, respectively. Since similar rmsd values were obtained in the superimposition among the six monomers or three dimers of the same apo- or holo-form, we can conclude that the observed differences are mainly related to a conformational intrinsic variability of CrGSNOR1 molecules rather than to specific conformational changes between apo- and holostructure. The comparison of CrGSNOR1 with other structurally known GSNORs (i.e. human, tomato and Arabidopsis GSNORs) clearly indicates a folding conservation with an almost identical secondary structure composition (Fig. 2) [35,47,66]. The mean rmsd values for dimers superimposition of apo-CrGSNOR1 with tomato apo-enzyme (PDB code 4DLA) is $0.83 \AA$ and similar values ( 0.92 and $1.03 \AA$ ) were obtained when $\mathrm{NAD}^{+}$-CrGSNOR1 was superimposed to holo-enzymes from tomato (PDB code 4DL9) and Arabidopsis (PDB code 4JJI), respectively. The comparison with human (Hs) apo- and holo-CrGSNOR gave rmsd values within the same range (0.92 and $0.84 \AA$, respectively). All GSNOR structures known so far are thus very similar, and the 

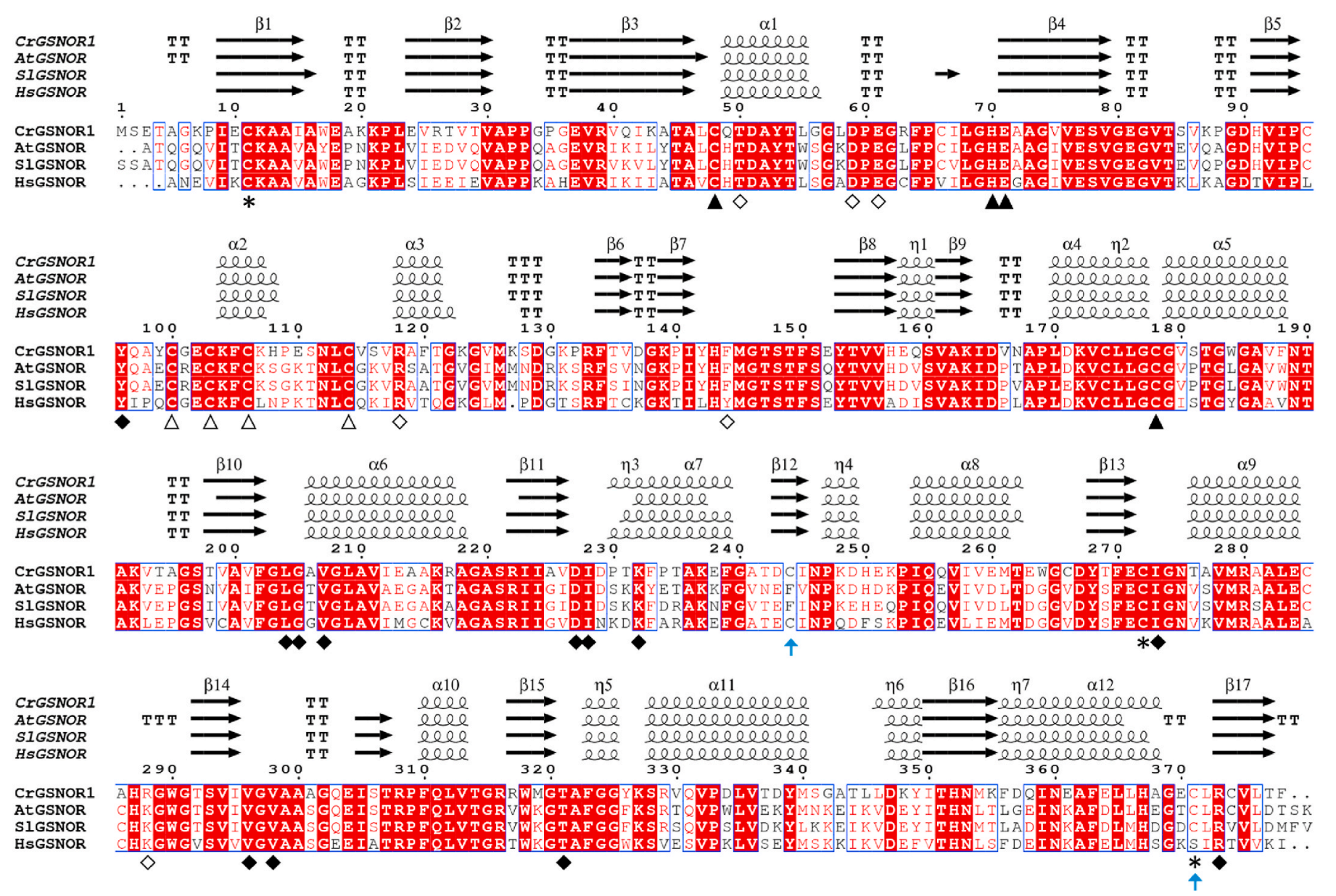

Fig. 2. Primary and secondary structure alignment of 3D-solved GSNORs. The alignment was performed with Espript (http://espript.ibcp.fr) [115] using the sequence and the structure of CrGSNOR1 (this work); GSNOR from Arabidopsis thaliana (AtGSNOR, PDB ID 3UKO); GSNOR from Solanum lycopersicum (SIGSNOR, PDB ID 4DLB), GSNOR from Homo sapiens (HsGSNOR, PDB ID 1M6H). The conserved residues are shown in red background; blue boxes represent conserved amino acid stretches $(>70 \%)$. Residues with similar physico-chemical properties are indicated in red. $\alpha$-helices, $\beta$-strands and $3_{10}$-helices are marked with $\alpha, \beta, \eta$ respectively. $\beta$-turns and $\alpha$-turns are represented by TT and TTT, respectively. Residues coordinating the catalytic and structural zinc atom are indicated by closed and open triangles, respectively. Closed and open diamonds denote residues interacting with the cofactor and substrate, respectively. An asterisk indicates putative cysteine targets of S-nitrosylation in AtGSNOR while a light-blue arrow indicates accessible cysteine residues in CrGSNOR1. The primary sequence alignment was made using Clustal Omega [116]. (For interpretation of the references to colour in this figure legend, the reader is referred to the Web version of this article.)

differences between species are, in terms of rmsd, comparable to the differences among CrGSNOR1 dimers of the same asymmetric unit.

The structural homology of CrGSNOR1 with other known GSNORs also embraces subunit composition. Indeed, each subunit is composed of a large catalytic domain comprising residues 1-177 and 327-377, and a smaller cofactor-binding domain (residues 178-326, Fig. 3B). The latter domain shows the typical Rossman fold formed by a six-stranded parallel $\beta$-sheet sandwiched among six $\alpha$-helices and an additional $\beta$-strand. This domain forms the internal dimer interface and is oriented in such a way that the six-stranded $\beta$-sheets of each subunit form a continuous $\beta$-sheet (Fig. 3A). The cofactor is stabilized by several hydrogen bonds with protein residues and water molecules, and a unique electrostatic interaction established between its nicotinamide phosphate group and Arg373 (Fig. 3C). The adenine ring is sandwiched between two isoleucine residues (Ile228 and Ile272) but does not form short interactions $(<3.5 \AA$ ) with protein residues (Fig. 3C and Supplemental Fig. 4A). The nicotinamide ring is kept in place by hydrophobic interactions with two valines (Val207 and Val298) and the methyl group of Thr182, and hydrogen bonds between its terminal amide group and the backbone carbonyl group of Val296 and Thr321, and amino group of Phe323 (Fig. 3C and Supplemental Fig. 4A).

\subsection{The catalytic domain of CrGSNOR1 allocates both the catalytic and structural zinc ions}

The catalytic domain of CrGSNOR1 contains two zinc ions. One zinc ion $(\mathrm{Zn} 402)$ is thought to have a structural role and it is coordinated with a tetrahedral geometry by four cysteine residues (Cys100, 103, 106 and 114) in both apo- and holo-forms (Fig. 4A). The second zinc ion (Zn401) lies in the active site and has a catalytic role as a Lewis acid, activating the functional group of the substrate. In $\mathrm{NAD}^{+}$-CrGSNOR1, it is coordinated with a tetrahedral geometry involving Cys48, Cys178, His70, and Glu71 (Fig. 4B). The identical geometry is maintained in one out of six subunits of the apo-structure (subunit F) with Glu71 replaced by a water molecule (or a hydroxide ion) (Fig. 4C). In the other subunits, the metal ion is coordinated by five ligands comprising the four aforementioned residues and one water molecule in chains $\mathrm{A}, \mathrm{B}, \mathrm{D}$ and $\mathrm{E}$ (Fig. 4D) or Cys48, Cys178, His70 and two water molecules in chain C (Fig. 4E). This penta-coordination formed a distorted trigonal bipyramidal geometry with the oxygen ligands from Glu71 and/or water molecules in the axial positions (i.e. perpendicular to the equatorial plane), while the nitrogen from His70 and the two sulfur ligands from Cys48 and Cys 178 are found on the equatorial plane forming $120^{\circ}$ angles. In both subunits F and C, the metal center lies at more than $4 \AA$ from Glu71 having its carboxylic group electrostatically interacting with 
A

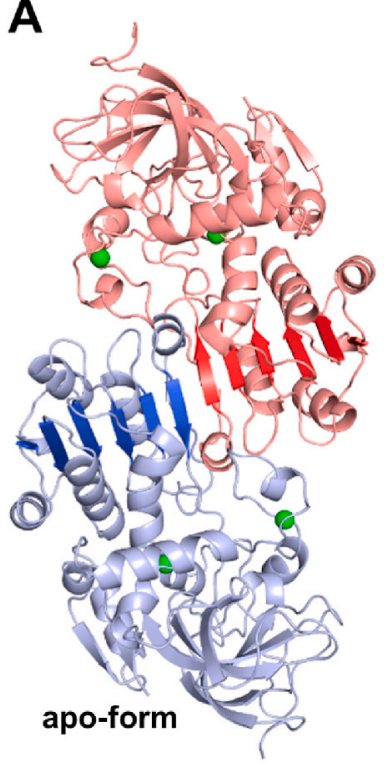

B

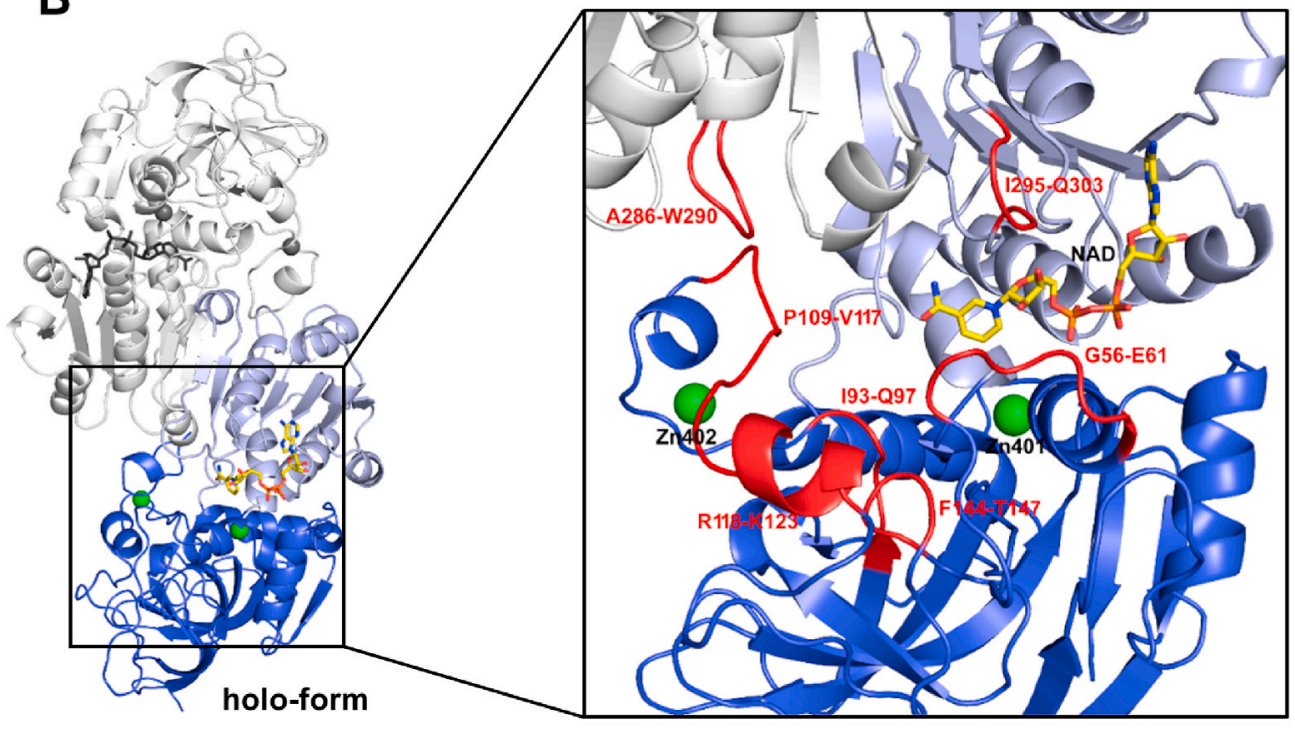

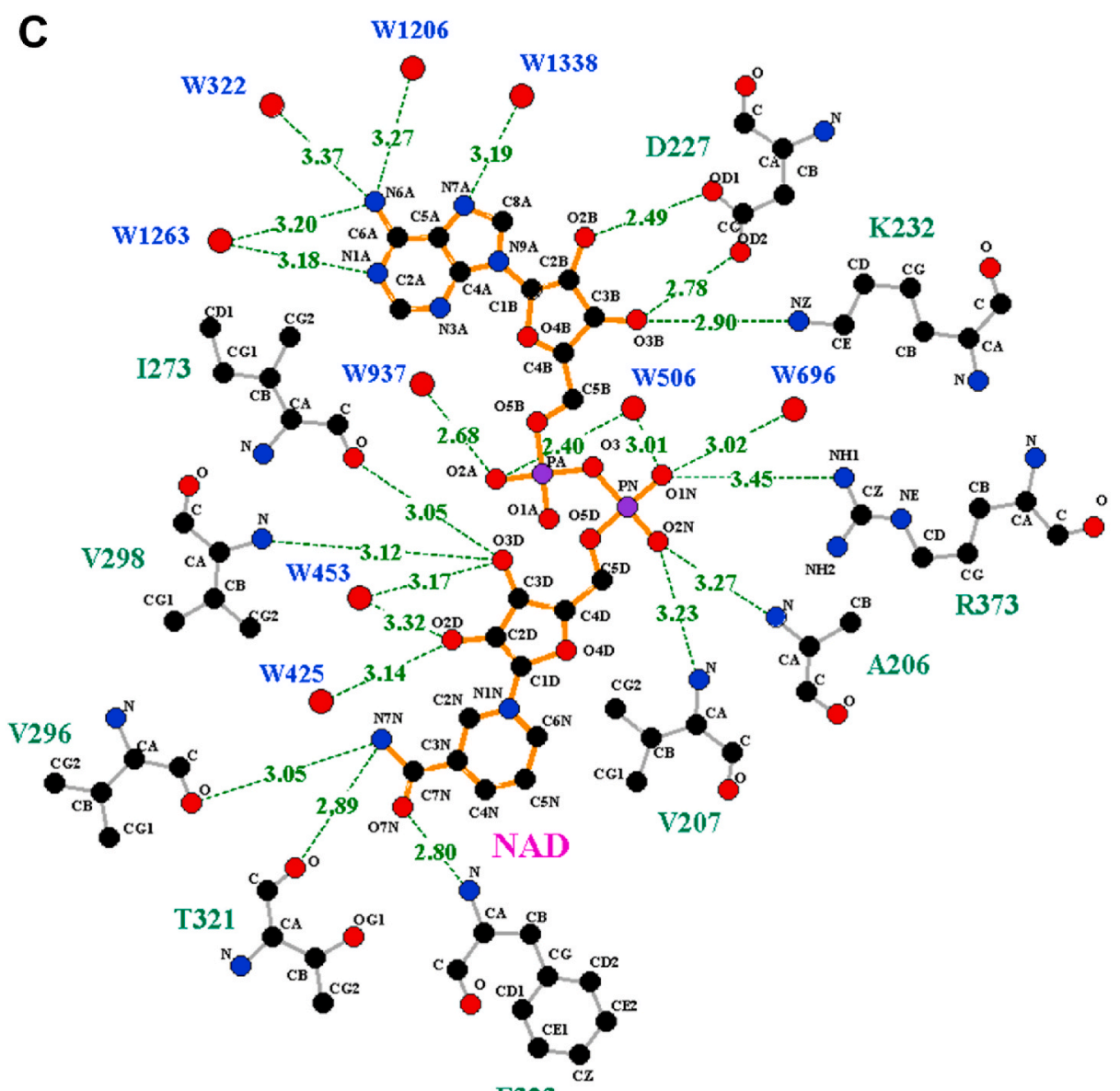

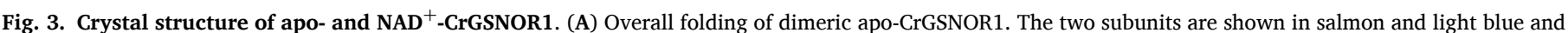

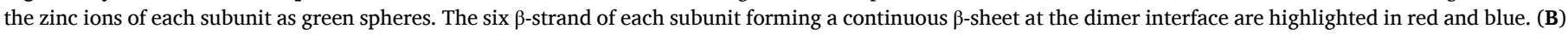

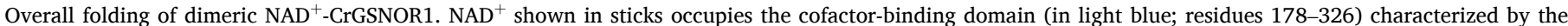

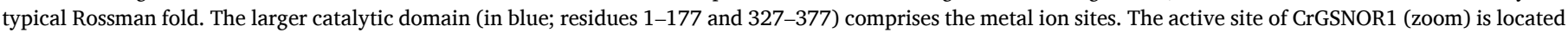

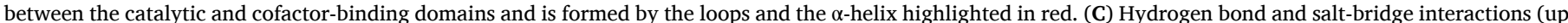

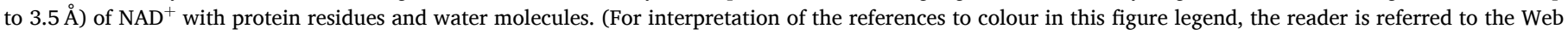
version of this article.) 

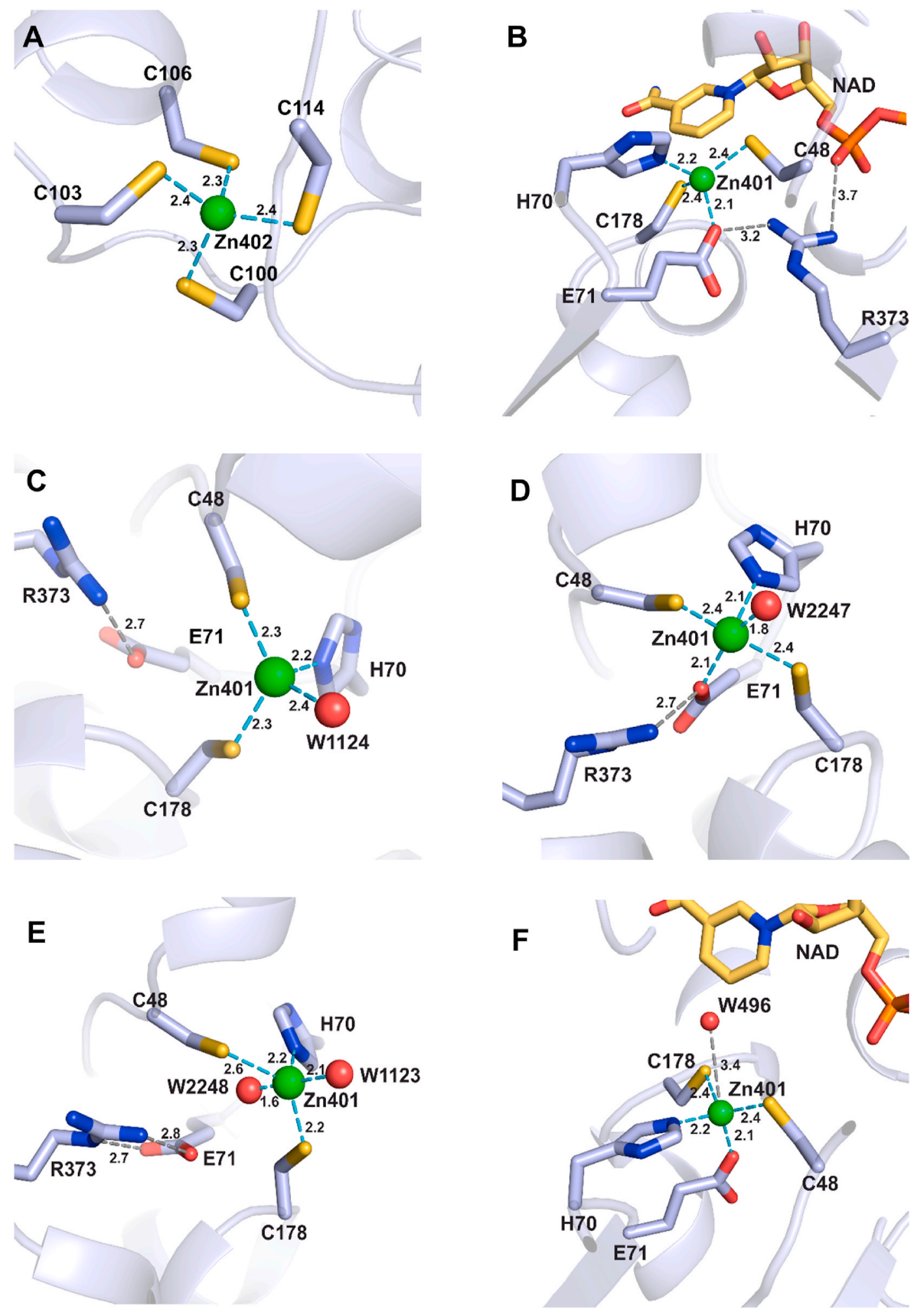

Fig. 4. Coordination environment of the zinc ions in apo- and NAD ${ }^{+}$-CrGSNOR1. (A) The structural zinc ion is coordinated by four cysteine residues (100,103, 106 and 114) in all subunits of both enzyme forms. (B) The catalytic zinc ion is coordinated with a tetrahedral geometry by two cysteines (48 and 178), His70, and Glu71 in all subunits of $\mathrm{NAD}^{+}$-CrGSNOR1. Glu71 also forms a salt-bridge with Arg373, which in turn interacts with the phosphate groups of the cofactor. (C) In F subunit of apo-CrGSNOR1, the catalytic zinc ion is coordinated with a distorted tetrahedral geometry by Cys48, Cys178, His70, and a water molecule. Glu71 is uniquely involved in a salt-bridge with Arg373. (D) In A, B, D and E subunits of apo-CrGSNOR1, the catalytic zinc ion is coordinated by five ligands comprising Cys48, Cys178, His70, Glu71 and a water molecule. Glu71 keeps its interaction with Arg373. (E) In the C subunit of apo-CrGSNOR1, the catalytic zinc ion is coordinated by five ligands comprising Cys48, Cys178, His70, and two water molecules. Glu71 is uniquely involved in double salt-bridge with Arg373. (F) In B and D subunits of $\mathrm{NAD}^{+}$-CrGSNOR1, in close proximity to the catalytic zinc ion coordinated with a tetrahedral geometry by Cys48, Cys178, His70, and Glu71, a water molecule is observed. 
Arg373 (Fig. 4C and E). This Glu-Arg salt-bridge is conserved also in the subunits where Glu71 participates in $\mathrm{Zn}^{2+}$ coordination (Fig. 4B and D). When the cofactor binds to the enzyme, Arg373 slightly moves toward the cofactor phosphate groups weakening the interaction with Glu71 that preferentially coordinates the zinc ion (Fig. 4B). However, in two subunits of the $\mathrm{NAD}^{+}$-structure (C and F subunits) the distance Glu71Zn401 is between 3.5 and $3.8 \AA$. Subunits superimposition shows that the increased Glu71-Zn401 distance observed in C and F subunits of both apo- and holo-forms is due to a 2-3 $\AA$ displacement of the zinc ion away from the glutamate toward the substrate-binding site (Supplemental Figs. $5 \mathrm{~A}$ and $5 \mathrm{~B}$ ) in a position superimposable to the catalytic zinc ion in HsGSNOR complexed with NADH and S-(hydroxymethyl)glutathione (HMGSH) [49] (Supplemental Fig. 5C). The reversible association of the catalytic zinc ion to Glu71 (i.e. far in apo-structure, close in holo-structure and far again in ternary complex-structure), was reported for tomato and human GSNOR [35,49], but its function in the catalytic cycle is still an open issue. This alternate zinc ion positioning is not observed in the four subunits of apo-CrGSNOR1 structure (A, B, D and E) where Glu71 participates in metal coordination (Supplemental Fig. 5D) and two subunits of the $\mathrm{NAD}^{+}$-CrGSNOR1 structure (C and F) where Glu71 is at a significantly higher distance than the other ligands (Supplemental Fig. 5B). Interestingly, in four out of six subunits of the holo-form (A, C, E, and F) no water molecule was observed in close proximity to the catalytic zinc ion as found in other GSNOR structures. By contrast, in B and D subunits a water molecule is located at about $3 \AA$ from the zinc ion at the opposite side with respect to Glu71 (Fig. 4F). In the apo-structure, this water molecule always participates in metal coordination being hydrogen-bonded to Thr50 and Tyr96 (distance ranging from 4.2 to $5.8 \AA$; Supplemental Fig. 6A). In all subunits of $\mathrm{NAD}^{+}$-CrGSNOR1 structure, the hydroxyl group of Tyr96 is rotated compared to the apo-form (Supplemental Figure 6B) and is not able to interact with the water molecule that partially loses its stabilization. Differently, Arabidopsis, tomato and human holo-structures always show a water molecule in the proximity of the catalytic zinc ion and the rotation of the conserved Tyr96 is not observed. When present, the water molecule bridges the zinc ion and the nicotinamide ring of the cofactor, which lies at about $5.0 \AA$ from the catalytic metal (Fig. 4F).

The active site is located between the catalytic and cofactor-binding domains (Fig. 3B) and is formed by several loops including Gly56-Glu61, Pro109-Val117, Ile93-Gln97, Phe144-Thr147, Ala286-Trp290 and Ile295-Gln303, and the $\alpha$-helix Arg118-Lys123 (Fig. 2). These portions contain residues involved in the binding of the substrate HMGSH in HsGSNOR [49,88,89]. Most of these residues are conserved among different GSNORs (Fig. 2), except for Gln112, Tyr140, and Lys284 (HsGSNOR numbering), which are replaced in CrGSNOR1 by Val115, Phe144, and Arg288, respectively (Fig. 2). Within the substrate-binding site of $\mathrm{NAD}^{+}$-CrGSNOR1 structure (chains A-F), we observed a PEG molecule from the crystallization medium that had a different length in the diverse chains. The terminal hydroxyl group of PEG is located at more than $5.5 \AA$ from the catalytic zinc ion and does not contribute to its coordination as observed for the hydroxyl group of HMGSH in HsGSNOR ternary complex [49]. Hydrogen bonds with Tyr96, Gln97, NAD ${ }^{+}$, and several water molecules stabilize PEG (Supplemental Fig. 4B). The rotation of Tyr96 side chain with respect to the position in the apo-structure is required for PEG accommodation into the substrate-binding site. An equivalent rotation is not observed in the HMGSH binding to HsGSNOR.

\subsection{Biochemical features of recombinant CrGSNOR1}

Purified recombinant CrGSNOR1 was assayed for its ability to catabolize GSNO. The enzyme-catalyzed GSNO degradation in the presence of NADH displaying a linear relationship with protein concentrations (Supplemental Fig. 7). By contrast, its activity was almost undetectable when NADPH replaced NADH (Fig. 5A). Likewise, no activity was observed by replacing GSNO with GSSG (Fig. 5B). These
A

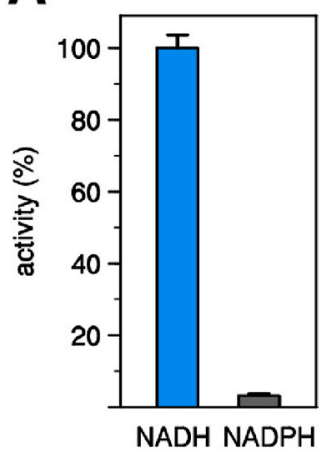

B

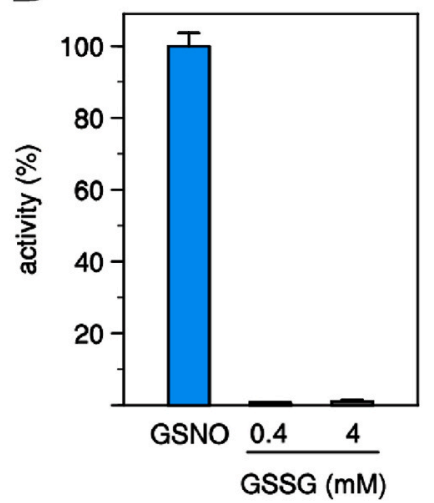

C

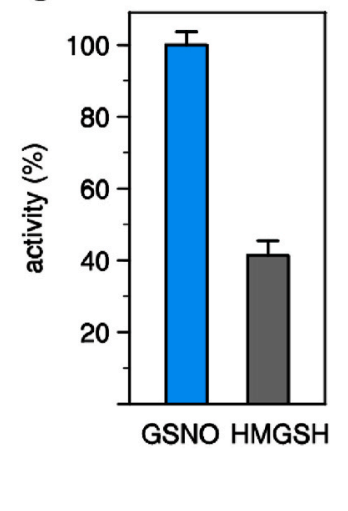

Fig. 5. Kinetic analysis of CrGSNOR1. (A) Cofactor specificity of CrGSNOR1 activity in the presence of GSNO. The activity of CrGSNOR was evaluated in the presence of $0.4 \mathrm{mM}$ GSNO using $0.2 \mathrm{mM} \mathrm{NADH}$ (white bar) or $0.2 \mathrm{mM}$ NADPH (black bar) as cofactor. Data are represented as mean $\pm S D(n=3)$. (B) Substrate specificity of CrGSNOR1 activity in the presence of NADH. The activity of CrGSNOR was evaluated in the presence of $0.2 \mathrm{mM}$ NADH using $0.4 \mathrm{mM}$ GSNO (white bar) or GSSG ( 0.4 or $4 \mathrm{mM}$, black bar) as substrate. Data are represented as mean $\pm S D \quad(n=3)$. (C) Activity of CrGSNOR1 as reductase or dehydrogenase. The activity of CrGSNOR was evaluated using GSNO (white bar) or HMGSH (black bar) as described in the Experimental section. Data are represented as mean $\pm \operatorname{SD}(n=3)$. For panels A-C, the NADH-dependent GSNO reduction of CrGSNOR1 (25 nM) was set to $100 \%$ $(36.9 \pm 2.9 \mu \mathrm{mol} / \mathrm{min} / \mathrm{mg})$. (D) Thermal stability of CrGSNOR1. The protein was incubated for $30 \mathrm{~min}$ at variable temperatures and after incubation, the remaining activity was measured. Data are represented as mean $\pm S D(n=3)$. (E) Inactivation treatments of CrGSNOR1 with MMTS or NEM. CrGSNOR1 was incubated for $30 \mathrm{~min}$ in the presence of $1 \mathrm{mM}$ MMTS or $1 \mathrm{mM} \mathrm{NEM} \mathrm{(grey} \mathrm{bars).} \mathrm{Data} \mathrm{are} \mathrm{repre-}$ sented as mean $\pm S D(n=3)$ of control activity measured after protein incubation in the presence of buffer alone (light-blue bar). (For interpretation of the references to colour in this figure legend, the reader is referred to the Web version of this article.) 
results indicate that CrGSNOR1 activity strictly depends on NADH and GSNO. GSNOR from diverse sources was originally found to catalyze the oxidation of S-(hydroxymethyl)glutathione (HMGSH) in the presence of $\mathrm{NAD}^{+} 32,35,41,49,90$. The Chlamydomonas GSNOR1 enzyme was also able to catalyze the NAD-dependent oxidation of HMGSH but with a 2.5-fold lower efficiency compared to the GSNO degrading activity (Fig. 5C).

Kinetic analyses were performed on the NADH-dependent GSNO reducing activity of CrGSNOR1 using either GSNO or NADH as variable substrates and the kinetic parameters were determined by non-linear regression analysis (Supplemental Figs. 8A and 8B). When the initial rates were plotted as a function of substrate concentration, responses were hyperbolic allowing apparent kinetic parameters to be calculated. The apparent Michaelis-Menten constants $\left(K^{\prime}{ }_{\mathrm{m}}\right)$ measured at saturating concentrations of the non-varied substrate were $24.9 \pm 1.5 \mu \mathrm{M}$ for GSNO and $14.3 \pm 2.1 \mu \mathrm{M}$ for NADH and the apparent turnover numbers ( $\left.k_{\text {cat }}\right)$ were $26.6 \pm 2.5 \mathrm{~s}^{-1}$ (GSNO) and $27.0 \pm 0.6 \mathrm{~s}^{-1}$ (NADH). The calculated catalytic efficiencies $\left(k_{\text {cat }}^{\prime} / K_{\mathrm{m}}^{\prime}\right)$ of the reaction were $\sim 1.07 \times 10^{6} \mathrm{M}^{-1} \mathrm{~s}^{-1}$ (GSNO) and $\sim 1.86 \times 10^{6} \mathrm{M}^{-1} \mathrm{~s}^{-1}$ (NADH). These values are comparable to previously characterized plant GSNORs although kinetic properties slightly differ for CrGSNOR1 with a $\sim 2-3$ fold higher substrate/cofactor affinities and $\sim 4-5$-fold lower turnover numbers [35,41,52,91].

After establishing the biochemical properties of recombinant CrGSNOR1, we analyzed its sensitivity to thermal denaturation as carried out with Chlamydomonas protein extracts. The thermal stability of recombinant CrGSNOR1 was investigated by following the residual GSNOR activity after $30 \mathrm{~min}$ incubation at different temperatures (Fig. 5D). The enzyme showed a relatively high degree of thermostability, retaining maximal activity in the $25-50{ }^{\circ} \mathrm{C}$ range. Exposure to higher temperatures led to a rapid protein inactivation being complete at temperatures above $65^{\circ} \mathrm{C}$. These observations correlate with the thermal sensitivity of the NADH-dependent activity measured in algal protein extracts (Fig. 1d). $\mathrm{T}_{50}$, the temperature at which $50 \%$ of the activity is retained after $30 \mathrm{~min}$ incubation, was found to be $\sim 56^{\circ} \mathrm{C}$, a value strikingly similar to other plant GSNORs [35,91]. The effect of temperature on CrGSNOR1 stability was also evaluated by following the turbidity at $405 \mathrm{~nm}$, which represents an optical measurement for protein denaturation/aggregation (Supplemental Fig. 8C). Consistent with activity measurements, CrGSNOR1 remained fully stable when incubated at $25^{\circ} \mathrm{C}$, whereas it started to aggregate immediately after incubation at $75{ }^{\circ} \mathrm{C}$, reaching maximal turbidity after $10 \mathrm{~min}$. At $55^{\circ} \mathrm{C}$, the aggregation kinetic proceeded more slowly and half-maximal turbidity was reached after $30 \mathrm{~min}$.

To further extend the comparison between the recombinant protein and the NADH-dependent enzymatic system from algal protein extracts, we examined the sensitivity of CrGSNOR1 to MMTS and NEM. Exposure of CrGSNOR1 to MMTS resulted in a complete inactivation of the enzyme, while NEM did not affect catalysis (Fig. 5E). This observation is in agreement with the catalytic effect of these two thiol-modifying compounds on algal protein extracts where NADH-dependent activity was only affected in the presence of MMTS (Fig. 1F). In protein extracts, however, the MMTS-dependent inactivation was only partial and this might be due to its reaction with thiol-containing proteins other than GSNORs. These results also indicate that CrGSNOR1 activity has a dissimilar response to MMTS and NEM, likely residing on the reactivity of MMTS with both solvent accessible and zinc-coordinating cysteines [87] thus affecting protein catalysis and/or structural stability.

\subsection{Cysteine conservation and thiol reactivity in CrGSNOR1}

CrGSNOR1 is a cysteine-rich enzyme as it contains sixteen cysteines that correspond to $4.2 \%$ of the total amino acid content (Supplemental Fig. 1). Among GSNORs from different species, nine out of sixteen cysteines are fully conserved comprising Cys48/Cys178 (coordination of the catalytic zinc atom), Cys100/Cys103/Cys106/Cys114 (coordination of the structural zinc atom) and Cys11 (except in bacterial GSNORs), Cys174 (except in C. elegans) and Cys272 (Fig. 2 and Supplemental Fig. 2). The remaining seven Cys are randomly conserved with Cys95/ Cys285/Cys371/Cys374 only present in the green lineage with the exceptions of Cys95 absent in pea GSNOR, Cys374 absent in the tomato and Lotus japonicus GSNOR1, and Cys285/Cys371 present in Synechocystis/yeast GSNOR, respectively. Cys244 is conserved in algae and most animals and bacteria (Fig. 2 and Supplemental Fig. 2). Despite the high Cys content, we found that CrGSNOR1 only contains two solvent accessible/reactive cysteine thiols as assessed by DTNB-based thiol titration $(2.0 \pm 0.3$ free thiols per subunit).

In order to confirm the number of accessible/reactive free thiols and establish their position, we analyzed the protein by matrix-assisted laser desorption ionization time-of-flight mass spectrometry (MALDI-TOF MS) following alkylation treatment in the presence of maleimide derivatives. Preliminary NEM-based alkylation experiments suggested that CrGSNOR1 was mainly di-alkylated (Supplemental Fig. 9). Nevertheless, the low mass shift induced by NEM $(+125$ Da per alkylated cysteine) precluded a clear separation of the different alkylated forms of CrGSNOR1 at the protein level. Therefore, NEM was replaced by Biotinmaleimide as it exhibits the same maleimide reactive group but allows better separation of the different protein species by generating a +451 Da mass shift per alkylated cysteine. As shown in Fig. 6, CrGSNOR1 underwent a near complete di-alkylation after $30 \mathrm{~min}$ incubation and longer incubation showed no further significant peaks. These data are consistent with the two accessible/reactive cysteine thiols determined by DTNB assay. Subsequently, we identified the alkylated cysteines by peptide mass fingerprinting of CrGSNOR1 treated with Biotinmaleimide for $20 \mathrm{~min}$. This incubation time was selected to generate partial mono- and di-alkylated species of CrGSNOR1. By comparing MALDI-TOF spectra obtained after trypsin digestion of untreated or Biotin-maleimide-treated CrGSNOR1, we identified Cys244 and Cys371 as alkylated residues (Fig. 7). Taking advantage of the presence of a biotin moiety, we also performed an enrichment of alkylated peptides using monomeric avidin as previously described in Refs. [67] and we confirmed the alkylation of Cys371 (Supplemental Fig. 10) while peptides containing Cys244 were not recovered likely due to its weak propensity to ionize under MALDI ionization conditions. Altogether, mass spectrometry analyses are consistent with the structural features of CrGSNOR1. Alkylation of Cys371 agrees with the high accessible surface area (ASA) calculated from the structure, ranging from $14 \AA^{2}$ to $31 \AA^{2}$ in different chains of the asymmetric unit. Similarly, Cys 244 has an accessibility in the 29-31 $\AA^{2}$ range, supporting its reactivity towards maleimide. The structure of the apo-form revealed that Cys272 is also exposed to the solvent (ASA $16-22 \AA^{2}$ ) but no alkylation was observed (Supplemental Fig. 11). This lack of reactivity may depend on the orientation of its thiol group toward a hydrophobic cavity (formed by Val187, 193, 201, 207, 211 and 296, Ala186, Gly208 and Phe270) that likely hampers reaction with maleimide derivatives. Conversely, the cofactor binding makes Cys272 completely buried in the holo-form.

\subsection{CrGSNOR1 has limited sensitivity to S-nitrosylation and remains unaffected by oxidative treatments}

Thiol-modifying treatments suggested that CrGSNOR1 contains cysteine(s) that might be prone to oxidative modifications that may affect enzyme catalysis. To investigate the sensitivity of CrGSNOR1 to physiological thiol-based modifications, we measured protein activity upon treatments with different molecules that specifically induce cysteine oxidation. As shown in Fig. 8A, diamide (TMAD) and hydrogen peroxide $\left(\mathrm{H}_{2} \mathrm{O}_{2}\right)$ did not significantly alter CrGSNOR1 activity even at a high concentration $(1 \mathrm{mM})$. Moreover, the number of accessible thiols does not change after treatment with $\mathrm{H}_{2} \mathrm{O}_{2}(1.9 \pm 0.1$ free thiols per subunit), and the CD spectra of CrGSNOR1 before and after treatment with $\mathrm{H}_{2} \mathrm{O}_{2}$ are superimposable (Supplemental Fig. 12A and Supplemental Table 2), ruling out significant variations of either the redox state 


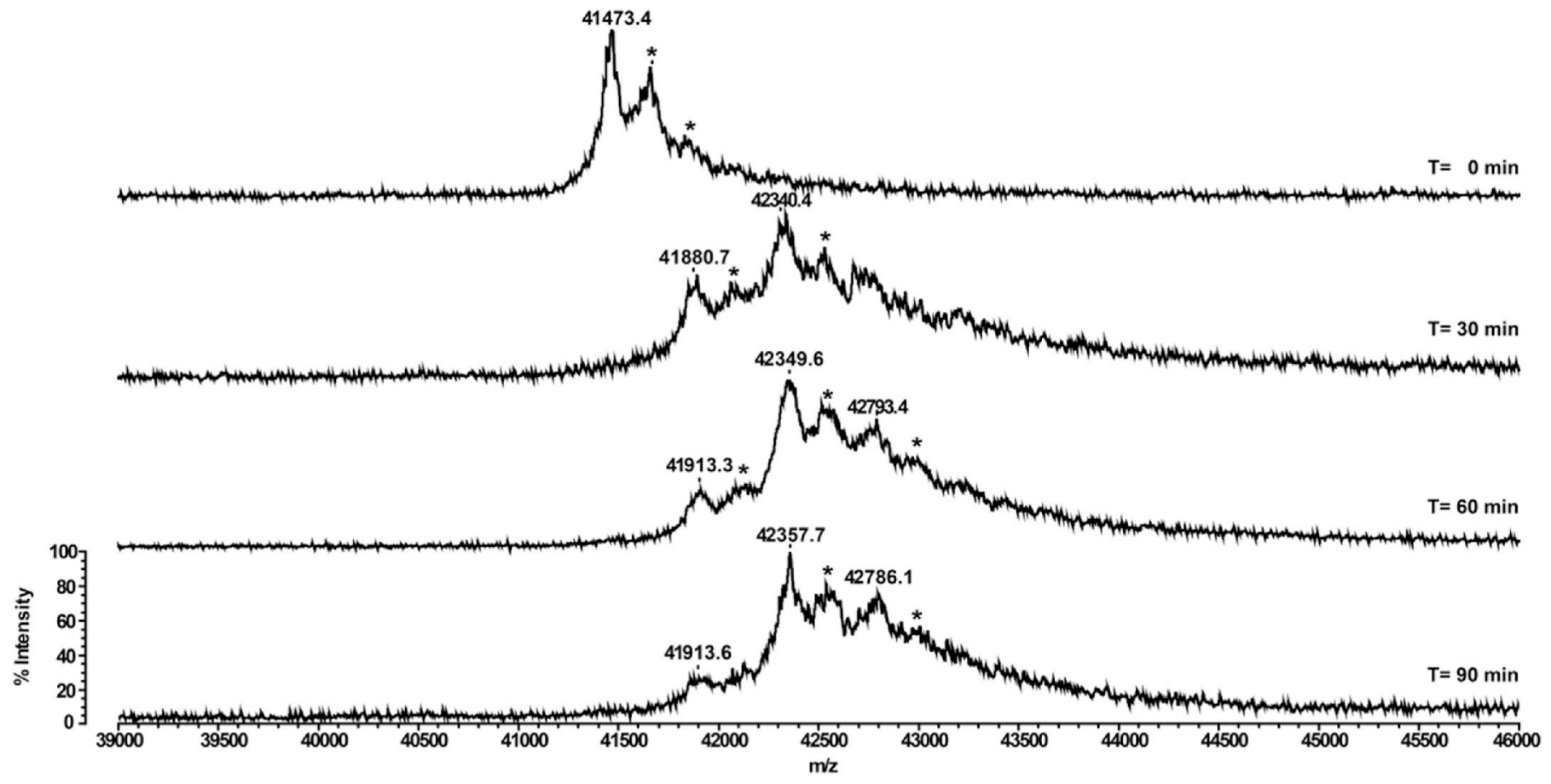

Fig. 6. Time-dependent mass spectrometry analyses of CrGSNOR1 treated with Biotin-maleimide. Recombinant CrGSNOR1 was incubated in the presence of $1 \mathrm{mM}$ Biotin-maleimide. At indicated time points, protein samples were withdrawn and analyzed by MALDI-TOF MS to assess the number of alkylated cysteines. For each alkylated cysteine, the molecular mass of CrGSNOR1 is shifted by +451 Da compared to the native protein (41473.4 Da). Peaks highlighted by an asterisk correspond to the protein-matrix (sinapinic acid) adduct. The y-axis is equal for all mass spectra acquired at times $0,30,60$, and 90 min, and only indicated in the bottom spectrum.

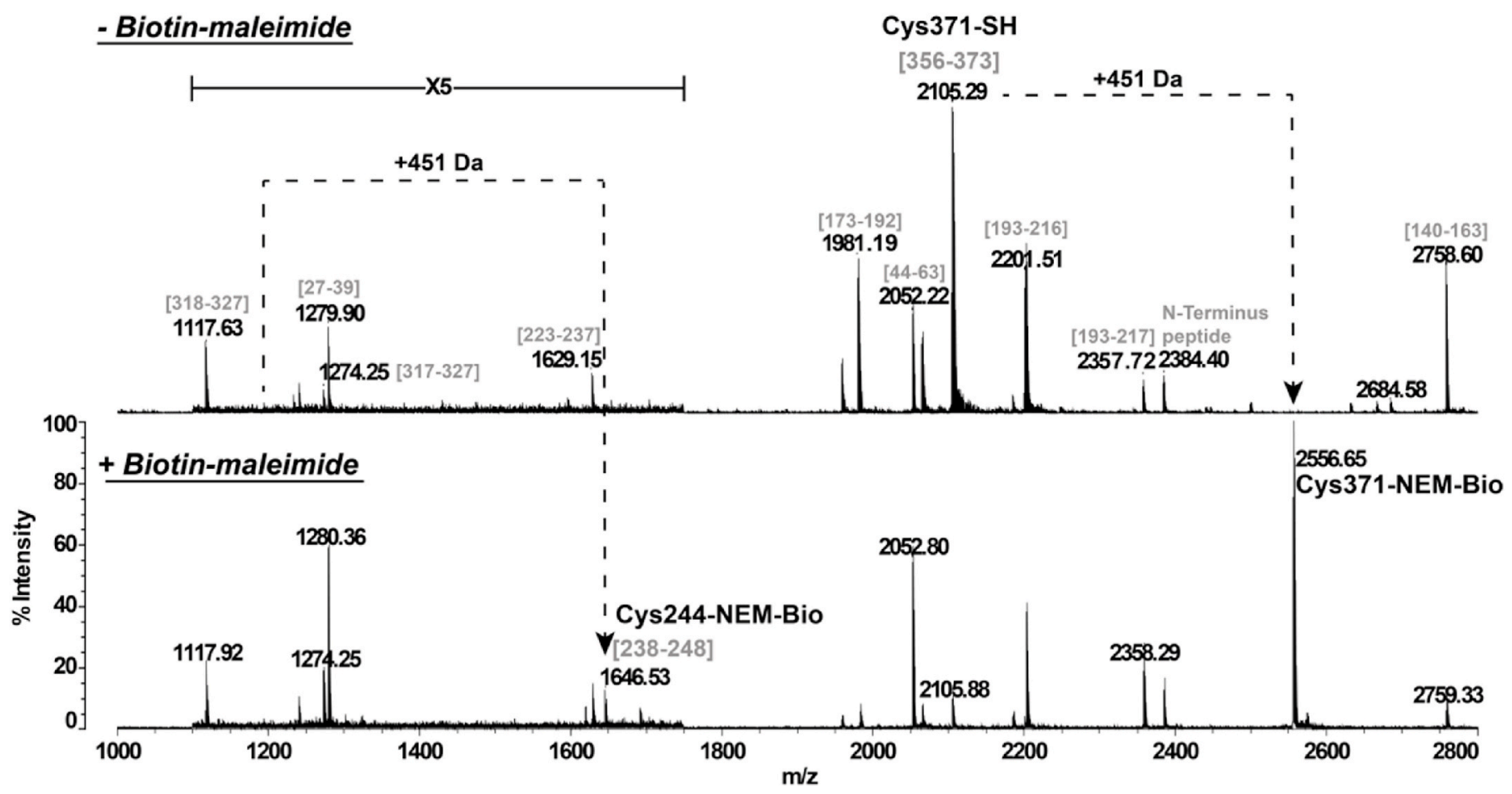

Fig. 7. Peptide mass fingerprinting of untreated or Biotin-maleimide-treated CrGSNOR1. Recombinant CrGSNOR1 was incubated in the presence of $1 \mathrm{mM}$ Biotin-maleimide for $20 \mathrm{~min}$ and then trypsin digested. The peptide mixture was analyzed by MALDI-TOF MS. Sequence of peptides belonging to CrGSNOR1 is indicated in brackets (numbering according to Fig. 2). Cysteines modified by Biotin-maleimide are annotated with the mention "NEM-Bio" and the peak corresponding to the peptide sequence [1-12] of CrGSNOR1 is indicated as N-terminus peptide as it is fused with the 7xHis affinity purification tag. 
A

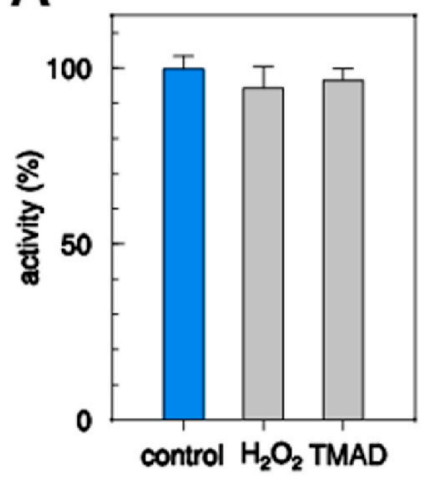

B

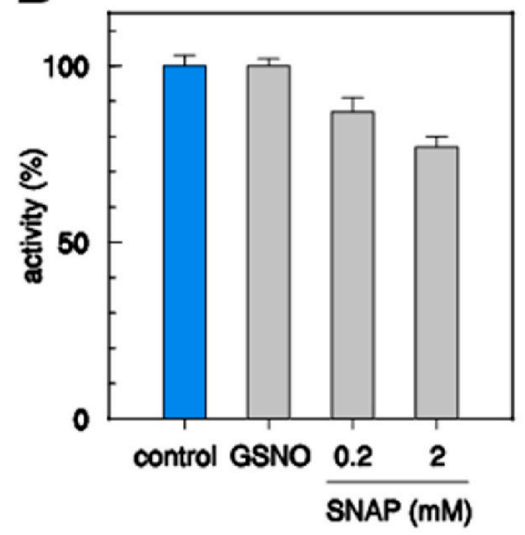

C

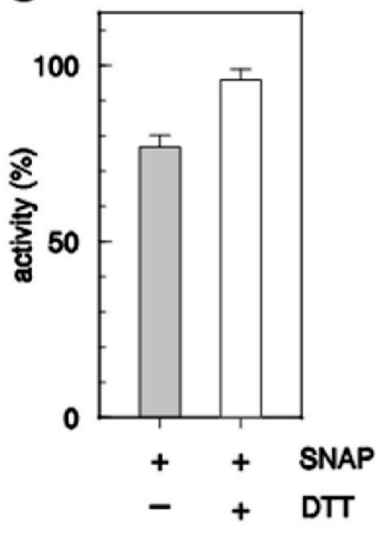

D

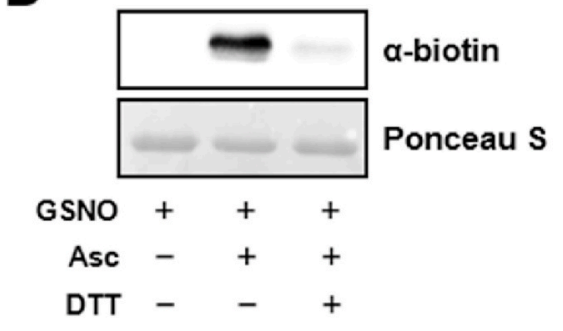

E

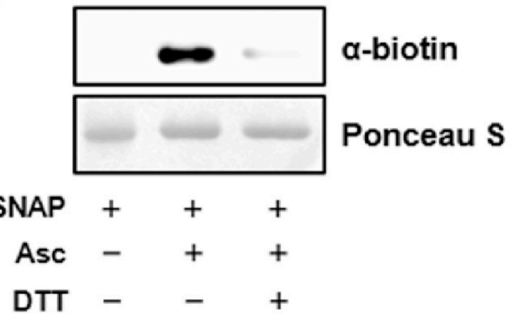

F

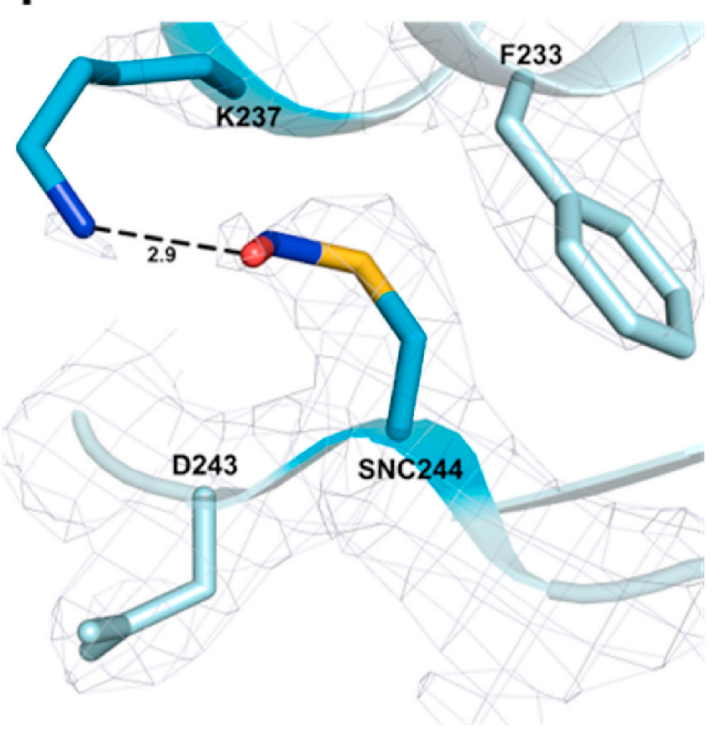

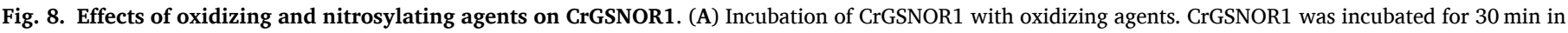

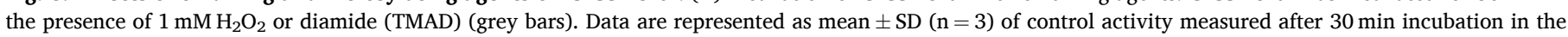

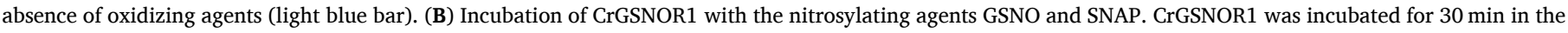

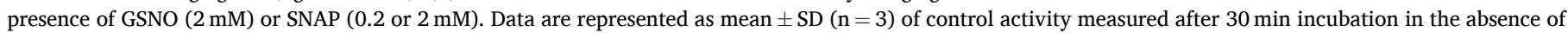

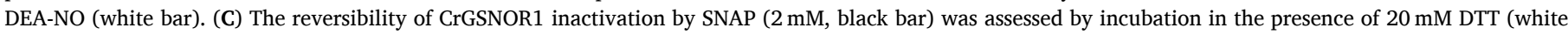

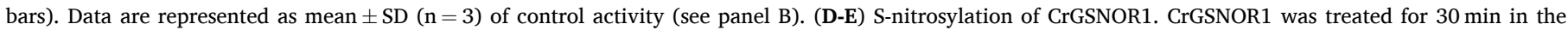

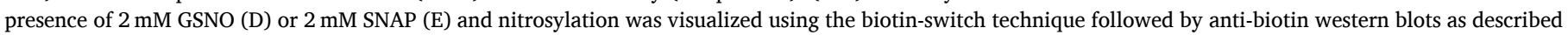

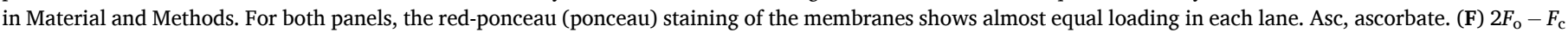

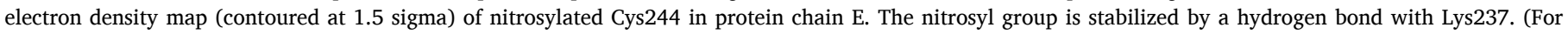
interpretation of the references to colour in this figure legend, the reader is referred to the Web version of this article.)

of accessible thiols or secondary structure upon the oxidative treatment. Previous studies reported that plant GSNORs undergo S-nitrosylation with consequent inhibition of nearly all isoforms with the exception of GSNOR1 and GSNOR2 from Lotus japonicus $[41,48,50-54,56]$. In order to examine whether S-nitrosylation can regulate CrGSNOR1, the purified enzyme was exposed to different types of NO-donors. Nitrosylation reactions were induced chemically with the NO-releasing compound SNAP or with GSNO that acts as a trans-nitrosylating agent [92]. In the presence of GSNO, the activity of CrGSNOR1 remained unaffected (Fig. 8B) while we observed a partial and reversible inhibition in the presence of SNAP (Fig. 8B and C). To assess the S-nitrosylation status of CrGSNOR1, we applied the biotin switch technique (BST) on the GSNOand SNAP-treated enzyme. Surprisingly, we observed a positive nitrosylation signal following exposure to both nitrosylating agents (Fig. 8D and E), indicating that either GSNO or SNAP can react with CrGSNOR1 cysteine(s) inducing S-nitrosylation. Despite the negligible effect on CrGSNOR1 catalysis, further biochemical and structural investigations were performed on the enzyme in the presence of GSNO considering its essential role as physiological NO donor. Thiol titration after treatment of CrGSNOR1 with GSNO indicates a decrease of accessible free thiols with respect to the untreated enzyme $(1.3 \pm 0.1$ free thiols per subunit). Moreover, the electron density obtained for a crystal of $\mathrm{NAD}^{+} / \mathrm{GS}$ NO-CrGSNOR1 clearly shows that the thiol group of Cys244 was nitrosylated (Fig. 8F), while no GSNO molecule was observed in the substrate binding site. In two (chains B and E) out of the six protein chains of the crystal asymmetric unit, the nitrosyl group is stabilized by a hydrogen bond with a water molecule or the amino group of Lys237 (Fig. 8F and Supplemental Fig. 13A). In chain A, the nitrosothiol is oriented toward a hydrophobic cavity formed by Leu204, Ile212, Ala225, Phe233 and Ala236 while in the remaining chains it is exposed to the solvent 
(Supplemental Figs. 13B-D). Compared to the holo-enzyme, the redox modification of Cys244 does not induce a significant conformational variation, as observed by CD spectroscopy analysis (Supplemental Fig. 12B), and the overall enzyme fold was also conserved (rmsd for the superimposition of $\mathrm{NAD}^{+}$-CrGSNOR1 and $\mathrm{NAD}^{+} / \mathrm{GSNO}-\mathrm{CrGSNOR} 1$ structures $=0.39 \AA$ ).

\section{Discussion}

Over the last decades, NO signaling has emerged as a fundamental process by which photosynthetic organisms including unicellular algae, regulate different aspects of cell metabolism $[7,14,93]$. Characterization of the mechanisms regulating NO homeostasis and NO-dependent signaling pathway, is of striking importance in microalgae considering their biotechnological potential for the bio-production of drugs, energy and food $[94,95]$. Recent efforts have set the foundations for the use of Chlamydomonas and other unicellular phototrophs as molecular chassis exploitable in the next synthetic biology-driven green revolution [96-98]. NO metabolism is of particular importance in these organisms living in liquid micro-oxic environments, where the fermentative metabolism and the Hemoglobin-NO cycle are important players in cellular bioenergy [99,100]. In Chlamydomonas, the biological function of NO relates to responses to nitrogen and sulfur starvation, hypoxia/anoxia, high light and light to dark transitions [4,58,60,99,101, 102]. In general, protein S-nitrosylation acts as the major mechanism propagating NO-dependent biological signaling and it can modulate protein function by altering enzymatic activity and/or protein structure [12-14,103]. Noteworthy, while NO-dependent biological pathways have been uncovered, very little is known about how microalgae control nitrosothiol homeostasis through NO catabolism.

Considering the primary role of GSNO as a trans-nitrosylating agent, the redox systems involved in GSNO catabolism are fundamental to control the intracellular levels of this low-molecular weight nitrosothiol and consequently, the extent of protein S-nitrosylation. In this work, we observed that Chlamydomonas protein extracts contain two distinct systems catalyzing GSNO reduction using NADPH or NADH and having different sensitivities to thiol-modifying compounds and thermal denaturation. Based on cofactor specificity and biochemical properties, we can hypothesize that the NADPH-dependent activity might primarily involve thiol-disulfide exchanges mediated by TRX or GRX $[28,29]$. Indeed, these enzymes are thermostable and their activity is inhibited by irreversible alkylation $[68,104]$. Similar properties are also found in glutathione reductases but these enzymes cannot use GSNO as a substrate ([105] and authors' personal communication). Other NADPH-dependent GSNO-reducing activities might be involved such as carbonyl reductase 1 and aldo-keto reductase family 1 member A1 identified in human [33,34] and for which orthologs are present in Chlamydomonas genome (data not shown). The NADH-dependent activity observed in Chlamydomonas protein extracts is most likely dependent on GSNOR since its sensitivity to thiol modifying agents and thermal denaturation is comparable to purified CrGSNOR1, which was found to strictly depend on GSNO and NADH (Figs. 1 and 5). This is further supported by an overall conservation of the three-dimensional structure of apo- and holo-CrGSNOR1 compared to other structurally known GSNORs. Despite this global structural homology, we observed that the coordination sphere of the catalytic zinc ion shows a high variability (Fig. 4B-F), while the tetrahedral thiolate-geometry $\left(\mathrm{S}_{4}\right)$ coordination of the structural zinc ion is perfectly conserved (Fig. 4A). When $\mathrm{NAD}^{+}$is bound to CrGSNOR1, the zinc atom is mainly coordinated by four conserved residues (Cys48, His70, Glu71 and Cys178; Figs. 2 and 4B) as in human, tomato, and Arabidopsis GSNORs. However, in two out of six subunits, the metal stabilization by Glu71 appears weaker with a distance above $3.5 \AA$. Indeed carboxylate groups can show a wide range of metal-ligand distances up to $4.5 \AA$ [106]. Differently, in the apo-structure the catalytic zinc is stabilized by four or five ligands involving Cys48, His70, Cys178, and Glu71 replaced or accompanied by one or two water molecules (or hydroxide ions; Fig. 4C-F). This expansion to a penta-coordination sphere, already reported for other zinc-containing proteins (e.g. adenosine deaminase [107]; astacin [108]) or temporarily occurring in catalytic zinc-sites to accommodate the substrate [109-111], was not observed in other structurally known GSNORs. The functional role of this increased dynamicity of the catalytic zinc in the algal enzyme possibly due to steric and stabilizing electrostatic interactions from the secondary coordination sphere, remains to be established.

GSNOR is typically defined as a cysteine-rich protein containing 14 to 16 Cys residues (Fig. 2 and Supplemental Fig. 2). Consistently, CrGSNOR1 contains 16 Cys of which only Cys244 and Cys371 were found to be solvent-exposed and reactive towards maleimide derivatives, although alkylation did not affect activity, in sharp contrast with AtGSNOR whose activity is strongly inhibited after exposure to alkylating agents [55]. While CrGSNOR1 is resistant to NEM, MMTS-dependent conjugation causes a rapid inactivation of the enzyme, which is likely ascribed to the ability of MMTS to alter zinc (s)-coordination with consequent protein inactivation. The response of CrGSNOR1 to thiol-based modifications reflects dissimilarities with other plant GSNORs [36,37]. Recent studies showed that GSNOR from several land plants was inhibited by both $\mathrm{H}_{2} \mathrm{O}_{2}$-dependent oxidation and S-nitrosylation $[48,50,51,53,56]$. Lindermayr and colleagues identified the catalytic zinc-coordinating cysteine residues (Cys47 and Cys177) as primary targets of $\mathrm{H}_{2} \mathrm{O}_{2}$-mediated oxidation in AtGSNOR with consequent zinc ion release and disruption of the catalytic site [55]. Although these cysteines are fully conserved in CrGSNOR1, treatments with $\mathrm{H}_{2} \mathrm{O}_{2}$ were found to be ineffective in altering either the redox state of accessible cysteines or protein activity and folding (Fig. 8 and Supplemental Fig. 12A). This suggests that CrGSNOR1 does not contain oxidation-prone free or zinc-bound cysteine(s), the latter being likely protected by a highly stable coordination in the algal enzyme. CrGSNOR1 was found to undergo S-nitrosylation but without any significant effect on GSNOR activity and native folding (Fig. 8 and Supplemental Fig. 12B), as previously observed for GSNORs from Lotus Japonicus [41]. By contrast, AtGSNOR was shown to undergo S-nitrosylation on Cys10, Cys271, and Cys370, leading to inhibition of the enzyme through a 2 -fold decrease of both the affinity towards GSNO and the turnover number [52]. These three residues are fully conserved in CrGSNOR1 (Figs. 2 and 9A), but alterations in cysteine microenvironments and local folding might explain the limited responsiveness of CrGSNOR1 to S-nitrosylation or other thiol modifications.

In CrGSNOR1, Cys11 is barely accessible, as in AtGSNOR, and not reactive toward alkylating reagents. Structural comparison between the two enzymes unveiled that despite a generally high backbone similarity, Cys11 in CrGSNOR1 is surrounded by specific residues (i.e. Glu10, Thr29, Asp137, Glu152 and the carboxyl group of C-terminal Phe377) that determine a negative electrostatic surface potential (Fig. 9B). These residues are not conserved in AtGSNOR1 (Fig. 2) where Cys10 is rather surrounded by positive charges (Fig. 9C) due to the N-terminal groups of Ala2, Lys11, Lys40 and Lys379 (the two latter not conserved in CrGSNOR1, Fig. 2). The differences between the microenvironment of Cys11/Cys10 in the two enzymes could be the basis for the lack of reactivity of this residue in CrGSNOR1. In vivo, nitrosylation of AtGSNOR Cys 10 occurs in response to hypoxia and promotes degradation of the enzyme by selective autophagy [53]. Recently, the non-canonical catalase CAT3 was shown to transnitrosylate AtGSNOR1 at Cys10, a process strictly dependent on CAT3 Cys343 [54]. This mechanism is unlikely to occur in Chlamydomonas since the previously cited cysteine is not conserved in the unique algal redox regulated catalase [112,113].

As observed for Cys370 in AtGSNOR [47], CrGSNOR1 Cys371 is exposed to the solvent, although its accessibility decreases from the apo-to the holo-form $\left(31-14 \AA^{2}\right.$ to $\left.15-5 \AA^{2}\right)$, and undergoes maleimide-dependent alkylation. Nevertheless, Cys371 alkylation has no effect on CrGSNOR1 activity. In both enzymes, Cys371/Cys370 lies in a loop that follows helix $\alpha 12$ and its thiol group forms various hydrogen 
A

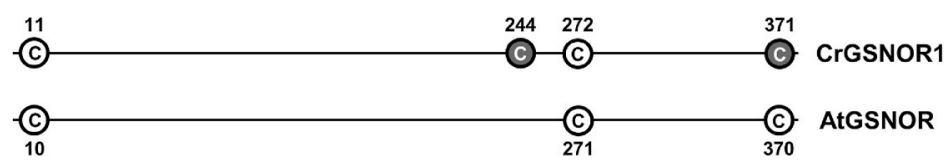

B
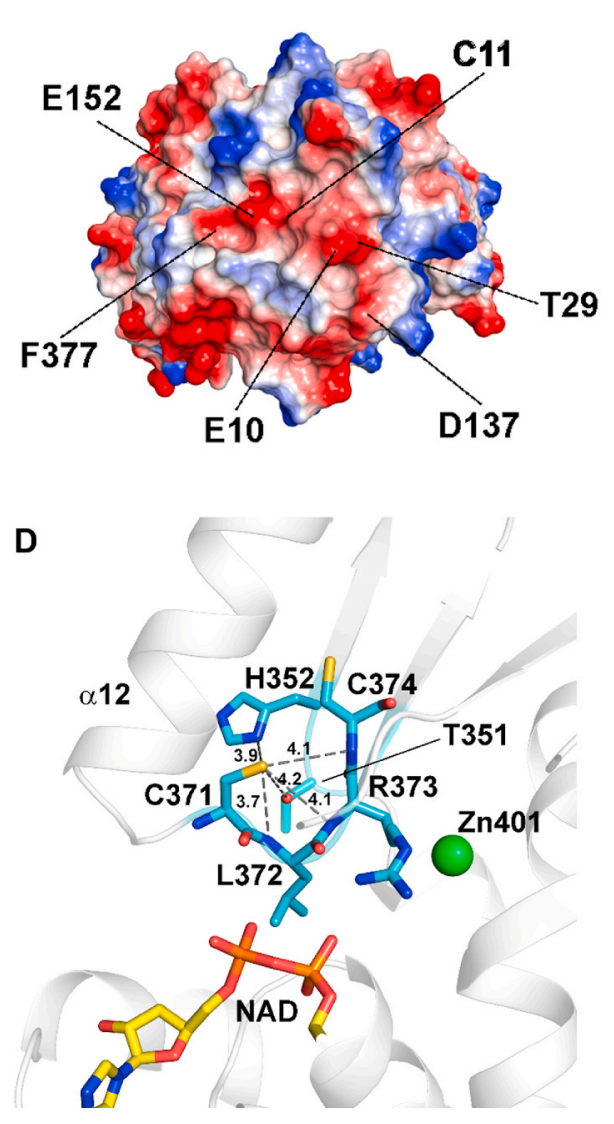

C
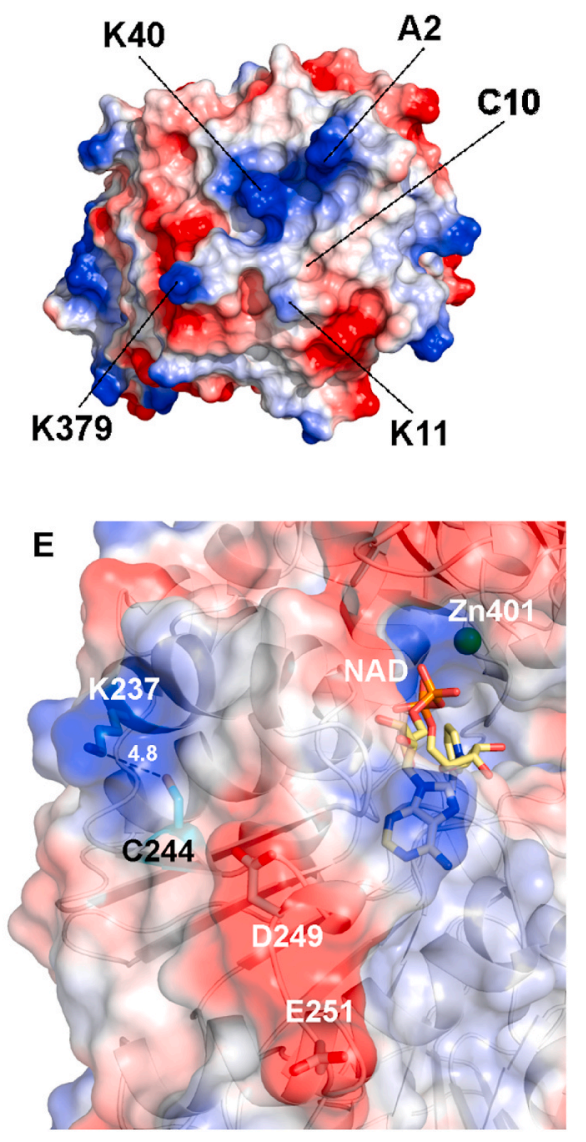

Fig. 9. Microenvironment of thiol-modified cysteine residues in algae and/or plant GSNORs. (A) Conservation of modified cysteine residues in CrGSNOR1 (alkylated Cys dark circle) and AtGSNOR (S-nitrosylated Cys white circle). Cys11 and Cys272 not modified in CrGSNOR1 are reported as a white circle. Electrostatic surface potential in the region surrounding Cys11 in CrGSNOR1 (B) and Cys10 in AtGSNOR (C). Specific residues determining the larger differences in surface potential between the two enzymes are indicated. The electrostatic surface potential ranges between -60 (red) and 60 (blue). (D) CrGSNOR1 Cys371 lies in a loop that follows helix $\alpha 12$. Its thiol group is hydrogen-bonded to the side chains and backbone nitrogen atoms of several surrounding residues. Cys371 overlooks the catalytic cavity containing the zinc ion and the cofactor. (E) The thiol group of CrGSNOR1 Cys244 is hydrogenbonded to the amino side chain group of Lys237, which determines a positive surface electrostatic potential. The carboxylic group of Asp249 and Glu251 determine a negative region on the other side of Cys244 thiol group. (For interpretation of the references to colour in this figure legend, the reader is referred to the Web version of this article.) bonds with surrounding residues (Figs. 2 and 9D). This region is characterized by high mobility expressed by backbone thermal parameters (B factors) larger than the average value for the whole protein (Supplemental Fig. 14 and Supplemental Table 1). However, in AtGSNOR, helix $\alpha 12$ is $3-4$ residues shorter compared to CrGSNOR1 thereby decreasing the structural constraints due to a rigid secondary structure and increasing the probability that a redox modification of the cysteine could induce a local conformational rearrangement affecting the catalytic activity. Indeed, this residue overlooks the cofactor binding pocket and lies at about 11-12 $\AA$ from the catalytic zinc ion (Fig. 9D). As observed for Cys371, also Cys272 (Cys271 in AtGSNOR) is solvent-accessible in CrGSNOR1. However, this residue becomes completely buried when $\mathrm{NAD}(\mathrm{H})$ is bound to the enzyme on the other side of the cofactor-binding pocket. By comparing the microenvironment of this residue, we observed that the region surrounding Cys272/Cys271 is structurally conserved between algal and plant enzymes. However, this residue is not modified by alkylation in CrGSNOR1 and we can thus suppose that physiological oxidative molecules cannot alter its redox state.

The other solvent-exposed cysteine targeted by maleimide alkylation in the Chlamydomonas enzyme, Cys244, is not conserved in GSNORs from land plants while it is present in other organisms including $V$. carteri, human, mouse, C. elegans, and prokaryotes such as E. coli and Synechocystis sp. PCC6803 (Fig. 2 and Supplemental Fig. 2). CrGSNOR1 Cys244 is hydrogen-bonded to Lys237 (Fig. 9E) and the presence of a positive region determined by Lys237 side chain in close proximity to the Cys244 thiol group and of a larger negative region due to Asp249 and Glu251, determines a specific microenvironment that can facilitate a proper binding of oxidative molecules (e.g. NO or GSNO). Consistently, structural observations show that GSNO cause S-nitrosylation of Cys244 (Fig. 8F) but, as observed for alkylating treatment, nitrosothiol formation did not alter the catalytic functioning of the enzyme, suggesting that modification of this residue is unlikely to control CrGSNOR1 activity.

\section{Conclusions}

In this study, we demonstrated that although CrGSNOR1 contains two accessible cysteines (Cy244 and Cys371) showing reactivity towards maleimide-based alkylation and to S-nitrosylation (only Cys244), its sensitivity to thiol-based oxidative modifications is null or limited compared to Arabidopsis GSNOR [52,55] and other homologues from land plants [56] with the notable exception of Lotus Japonicus GSNORs [41]. Deep analyses of the crystallographic structure of CrGSNOR1 revealed structural features likely responsible for the difference in Cys reactivity compared to plant enzymes. Indeed, cysteine reactivity does not reflect the absolute solvent accessibility of the residue and is also influenced by the cysteine microenvironment or local folding. Specifically, these structural features can (i) protect the residues from oxidative attacks, (ii) hamper proper allocation of oxidative compounds, and (iii) limit conformational changes that might directly affect protein 
catalysis or favor the redox sensitivity of other cysteine residues. The limited sensitivity of CrGSNOR1 to redox post-translational modifications suggests that regulation of NO signaling in algae may operate through other mechanisms including regulation of GSNOR by other modifications or by regulation of protein abundance and gene expression. GSNOR may also be constitutively active in algae, regulation of nitrosothiols abundance being controlled by other NO degrading enzymes or at the level of NO production. These differences are likely linked to distinct requirements for regulation of NO metabolism between land plants and algae.

S-nitrosylation of Cys244 does not appear to control CrGSNOR1 activity but may be instrumental to trigger in vivo moonlight functions unrelated to GSNOR activity, as already shown for the S-nitrosylation of AtGSNOR Cys10 ${ }^{53}$ and oxidation of glycolytic GAPDHs from both human and plant cells [114]. It will be interesting to investigate such functions in the future and to determine whether they could be shared with other species as suggested by the conservation of Cys244 in GSNORs from other eukaryotes (e.g. human, mouse, C. elegans, and V. carteri) and prokaryotes (e.g. E. coli and Synechocystis sp. PCC6803).

\section{Author contribution}

AT, JR, CHM, SDL, SF, and MZ designed the research; AT, JR, CHM, MDM, DT, GL, MM, SF, and MZ performed the research; AT, JR, CHM, MDM, DT, SDL, SF, and MZ analyzed the data; and AT, JR, CHM, DT, $\mathrm{SDL}, \mathrm{SF}$, and MZ wrote the paper. All authors have read and agreed to the current version of the manuscript.

\section{Declaration of competing interest}

We declare no conflict of interest.

\section{Acknowledgments}

We gratefully acknowledge Elettra and the European Synchrotron Radiation Facility (ESRF) for allocation of beam time. SF and GF thank the Consorzio Interuniversitario di Ricerca in Chimica dei Metalli nei Sistemi Biologici (CIRCMSB). This work was supported by University of Bologna Alma Idea 2017 Program (to DT and MZ); CNRS Sorbonne Université, Agence Nationale de la Recherche Grant 17-CE05-0001 CalvinDesign (to CHM and SDL); LABEX DYNAMO (ANRLABX-011 to CHM, MDM, and SDL) and EQUIPEX CACSICE (ANR-11-EQPX-0008 to CHM and SDL), partly through funding of the Proteomic Platform IBPC (PPI). JR and MM are supported by PhD grants from the University of Bologna ( $\mathrm{PhD}$ program in Cellular and Molecular Biology). The paper is published with the contribution of the Department of Excellence program financed by the Minister of Education, University and Research (MIUR, L. 232 del 01/12/2016)

\section{Appendix A. Supplementary data}

Supplementary data to this article can be found online at https://doi. org/10.1016/j.redox.2020.101806.

\section{References}

[1] S. Neill, R. Barros, J. Bright, R. Desikan, J. Hancock, J. Harrison, P. Morris, D. Ribeiro, I. Wilson, Nitric oxide, stomatal closure, and abiotic stress, J. Exp. Bot. 59 (2008) 165-176.

[2] D. Bellin, S. Asai, M. Delledonne, H. Yoshioka, Nitric oxide as a mediator for defense responses, Mol. Plant Microbe Interact. 26 (2013) 271-277.

[3] B. Li, L. Sun, J. Huang, C. Goschl, W. Shi, J. Chory, W. Busch, GSNOR provides plant tolerance to iron toxicity via preventing iron-dependent nitrosative and oxidative cytotoxicity, Nat. Commun. 10 (2019) 3896.

[4] E.Y. Kuo, H.L. Chang, S.T. Lin, T.M. Lee, High light-induced nitric oxide production induces autophagy and cell death in Chlamydomonas reinhardtii, Front. Plant Sci. 11 (2020) 772

[5] S. Umbreen, J. Lubega, B. Cui, Q. Pan, J. Jiang, G.J. Loake, Specificity in nitric oxide signalling, J. Exp. Bot. 69 (2018) 3439-3448.
[6] A. Ageeva-Kieferle, E.E. Rudolf, C. Lindermayr, Redox-dependent chromatin remodeling: a new function of nitric oxide as architect of chromatin structure in plants, Front. Plant Sci. 10 (2019) 625.

[7] F. Del Castello, A. Nejamkin, R. Cassia, N. Correa-Aragunde, B. Fernandez, N. Foresi, C. Lombardo, L. Ramirez, L. Lamattina, The era of nitric oxide in plant biology: twenty years tying up loose ends, Nitric Oxide 85 (2019) 17-27.

[8] Z. Yu, J. Cao, S. Zhu, L. Zhang, Y. Peng, J. Shi, Exogenous nitric oxide enhances disease resistance by nitrosylation and inhibition of S-nitrosoglutathione reductase in Peach Fruit, Front. Plant Sci. 11 (2020) 543.

[9] J.C. Begara-Morales, B. Sanchez-Calvo, M. Chaki, R. Valderrama, C. Mata-Perez, M.N. Padilla, F.J. Corpas, J.B. Barroso, Antioxidant systems are regulated by nitric oxide-mediated post-translational modifications (NO-PTMs), Front. Plant Sci. 7 (2016) 152

[10] A. Besson-Bard, A. Pugin, D. Wendehenne, New insights into nitric oxide signaling in plants, Annu. Rev. Plant Biol. 59 (2008) 21-39.

[11] K.J. Gupta, Z. Kolbert, J. Durner, C. Lindermayr, F.J. Corpas, R. Brouquisse, J. B. Barroso, S. Umbreen, J.M. Palma, J.T. Hancock, M. Petrivalsky, D. Wendehenne, G.J. Loake, Regulating the regulator: nitric oxide control of posttranslational modifications, New Phytol. 227 (2020) 1319-1325.

[12] J. Feng, L. Chen, J. Zuo, Protein S-Nitrosylation in plants: current progresses and challenges, J. Integr. Plant Biol. 61 (2019) 1206-1223.

[13] M. Zaffagnini, S. Fermani, C.H. Marchand, A. Costa, F. Sparla, N. Rouhier, P. Geigenberger, S.D. Lemaire, P. Trost, Redox homeostasis in photosynthetic organisms: novel and established thiol-based molecular mechanisms, Antioxidants Redox Signal. 31 (2019) 155-210.

[14] M. Zaffagnini, M. De Mia, S. Morisse, N. Di Giacinto, C.H. Marchand, A. Maes, S. D. Lemaire, P. Trost, Protein S-nitrosylation in photosynthetic organisms: a comprehensive overview with future perspectives, Biochim. Biophys. Acta 1864 (2016) 952-966.

[15] M. Yu, L. Lamattina, S.H. Spoel, G.J. Loake, Nitric oxide function in plant biology: a redox cue in deconvolution, New Phytol. 202 (2014) 1142-1156.

[16] J. Astier, A. Kulik, E. Koen, A. Besson-Bard, S. Bourque, S. Jeandroz, O. Lamotte, D. Wendehenne, Protein S-nitrosylation: what's going on in plants? Free Radic. Biol. Med. 53 (2012) 1101-1110.

[17] S. Morisse, M. Zaffagnini, X.H. Gao, S.D. Lemaire, C.H. Marchand, Insight into protein S-nitrosylation in Chlamydomonas reinhardtii, Antioxidants Redox Signal. 21 (2014) 1271-1284.

[18] M. Zaffagnini, L. Michelet, C. Sciabolini, N. Di Giacinto, S. Morisse, C. H. Marchand, P. Trost, S. Fermani, S.D. Lemaire, High-resolution crystal structure and redox properties of chloroplastic triosephosphate isomerase from Chlamydomonas reinhardtii, Mol. Plant 7 (2014) 101-120.

[19] D. Huang, J. Huo, J. Zhang, C. Wang, B. Wang, H. Fang, W. Liao, Protein Snitrosylation in programmed cell death in plants, Cell. Mol. Life Sci. 76 (2019) 1877-1887.

[20] M.J. Skelly, S.I. Malik, T. Le Bihan, Y. Bo, J. Jiang, S.H. Spoel, G.J. Loake, A role for S-nitrosylation of the SUMO-conjugating enzyme SCE1 in plant immunity, Proc. Natl. Acad. Sci. U. S. A. 116 (2019) 17090-17095.

[21] C. Lindermayr, G. Saalbach, J. Durner, Proteomic identification of S-nitrosylated proteins in Arabidopsis, Plant Physiol. 137 (2005) 921-930.

[22] M. Zaffagnini, S. Morisse, M. Bedhomme, C.H. Marchand, M. Festa, N. Rouhier, S. D. Lemaire, P. Trost, Mechanisms of nitrosylation and denitrosylation of cytoplasmic glyceraldehyde-3-phosphate dehydrogenase from Arabidopsis thaliana, J. Biol. Chem. 288 (2013) 22777-22789.

[23] N. Rouhier, S.D. Lemaire, J.P. Jacquot, The role of glutathione in photosynthetic organisms: emerging functions for glutaredoxins and glutathionylation, Annu. Rev. Plant Biol. 59 (2008) 143-166.

[24] G. Noctor, A. Mhamdi, S. Chaouch, Y. Han, J. Neukermans, B. Marquez-Garcia, G. Queval, C.H. Foyer, Glutathione in plants: an integrated overview, Plant Cell Environ. 35 (2012) 454-484.

[25] M. Airaki, L. Sanchez-Moreno, M. Leterrier, J.B. Barroso, J.M. Palma, F.J. Corpas, Detection and quantification of S-nitrosoglutathione (GSNO) in pepper (Capsicum annuum L.) plant organs by LC-ES/MS, Plant Cell Physiol. 52 (2011) 2006-2015.

[26] F.J. Corpas, J.D. Alche, J.B. Barroso, Current overview of S-nitrosoglutathione (GSNO) in higher plants, Front. Plant Sci. 4 (2013) 126.

[27] K.A. Broniowska, A.R. Diers, N. Hogg, S-Nitrosoglutathione, Biochim. Biophys. Acta 1830 (2013) 3173-3181.

[28] R. Sengupta, A. Holmgren, The role of thioredoxin in the regulation of cellular processes by S-nitrosylation, Biochim. Biophys. Acta 1820 (2012) 689-700.

[29] X. Ren, R. Sengupta, J. Lu, J.O. Lundberg, A. Holmgren, Characterization of mammalian glutaredoxin isoforms as S-denitrosylases, FEBS Lett. 593 (2019) 1799-1806.

[30] O.V. Lushchak, N.Z. Nykorak, T. Ohdate, Y. Inoue, V.I. Lushchak, Inactivation of genes encoding superoxide dismutase modifies yeast response to Snitrosoglutathione-induced stress, Biochemistry (Mosc.) 74 (2009) 445-451.

[31] A. Okado-Matsumoto, I. Fridovich, Putative denitrosylase activity of Cu, Znsuperoxide dismutase, Free Radic. Biol. Med. 43 (2007) 830-836.

[32] L. Liu, A. Hausladen, M. Zeng, L. Que, J. Heitman, J.S. Stamler, A metabolic enzyme for S-nitrosothiol conserved from bacteria to humans, Nature 410 (2001) 490-494.

[33] R.L. Bateman, D. Rauh, B. Tavshanjian, K.M. Shokat, Human carbonyl reductase 1 is an S-nitrosoglutathione reductase, J. Biol. Chem. 283 (2008) 35756-35762.

[34] C.T. Stomberski, P. Anand, N.M. Venetos, A. Hausladen, H.L. Zhou, R.T. Premont, J.S. Stamler, AKR1A1 is a novel mammalian S-nitroso-glutathione reductase, J. Biol. Chem. 294 (2019) 18285-18293.

[35] L. Kubienova, D. Kopecny, M. Tylichova, P. Briozzo, J. Skopalova, M. Sebela, M. Navratil, R. Tache, L. Luhova, J.B. Barroso, M. Petrivalsky, Structural and 
functional characterization of a plant S-nitrosoglutathione reductase from Solanum lycopersicum, Biochimie 95 (2013) 889-902.

[36] C. Lindermayr, Crosstalk between reactive oxygen species and nitric oxide in plants: key role of S-nitrosoglutathione reductase, Free Radic. Biol. Med. 122 (2018) 110-115.

[37] J. Jahnova, L. Luhova, M. Petrivalsky, S-nitrosoglutathione reductase-the master regulator of protein S-nitrosation in plant NO signaling, Plants (Basel) 8 (2019).

[38] A. Feechan, E. Kwon, B.W. Yun, Y. Wang, J.A. Pallas, G.J. Loake, A central role for S-nitrosothiols in plant disease resistance, Proc. Natl. Acad. Sci. U. S. A. 102 (2005) 8054-8059.

[39] M.W. Foster, L. Liu, M. Zeng, D.T. Hess, J.S. Stamler, A genetic analysis of nitrosative stress, Biochemistry 48 (2009) 792-799.

[40] L. Liu, Y. Yan, M. Zeng, J. Zhang, M.A. Hanes, G. Ahearn, T.J. McMahon, T. Dickfeld, H.E. Marshall, L.G. Que, J.S. Stamler, Essential roles of S-nitrosothiols in vascular homeostasis and endotoxic shock, Cell 116 (2004) 617-628.

[41] M.A. Matamoros, M.C. Cutrona, S. Wienkoop, J.C. Begara-Morales, N. Sandal, I. Orera, J.B. Barroso, J. Stougaard, M. Becana, Altered plant and nodule development and protein S-nitrosylation in Lotus japonicus mutants deficient in S-nitrosoglutathione reductases, Plant Cell Physiol. 61 (2020) 105-117.

[42] A. Lin, Y. Wang, J. Tang, P. Xue, C. Li, L. Liu, B. Hu, F. Yang, G.J. Loake, C. Chu, Nitric oxide and protein S-nitrosylation are integral to hydrogen peroxideinduced leaf cell death in rice, Plant Physiol. 158 (2012) 451-464.

[43] A. Sakamoto, M. Ueda, H. Morikawa, Arabidopsis glutathione-dependent formaldehyde dehydrogenase is an S-nitrosoglutathione reductase, FEBS Lett. 515 (2002) 20-24.

[44] D.E. Jensen, G.K. Belka, G.C. Du Bois, S-Nitrosoglutathione is a substrate for rat alcohol dehydrogenase class III isoenzyme, Biochem. J. 331 (Pt 2) (1998) 659-668.

[45] U. Lee, C. Wie, B.O. Fernandez, M. Feelisch, E. Vierling, Modulation of nitrosative stress by S-nitrosoglutathione reductase is critical for thermotolerance and plant growth in Arabidopsis, Plant Cell 20 (2008) 786-802.

[46] S.S. Merchant, S.E. Prochnik, O. Vallon, E.H. Harris, S.J. Karpowicz, G.B. Witman, A. Terry, A. Salamov, L.K. Fritz-Laylin, L. Marechal-Drouard, W.F. Marshall, L. H. Qu, D.R. Nelson, A.A. Sanderfoot, M.H. Spalding, V.V. Kapitonov, Q. Ren, P. Ferris, E. Lindquist, H. Shapiro, S.M. Lucas, J. Grimwood, J. Schmutz, P. Cardol, H. Cerutti, G. Chanfreau, C.L. Chen, V. Cognat, M.T. Croft, R. Dent, S. Dutcher, E. Fernandez, H. Fukuzawa, D. Gonzalez-Ballester, D. GonzalezHalphen, A. Hallmann, M. Hanikenne, M. Hippler, W. Inwood, K. Jabbari, M. Kalanon, R. Kuras, P.A. Lefebvre, S.D. Lemaire, A.V. Lobanov, M. Lohr, A. Manuell, I. Meier, L. Mets, M. Mittag, T. Mittelmeier, J.V. Moroney, J. Moseley, C. Napoli, A.M. Nedelcu, K. Niyogi, S.V. Novoselov, I.T. Paulsen, G. Pazour, S. Purton, J.P. Ral, D.M. Riano-Pachon, W. Riekhof, L. Rymarquis, M. Schroda, D. Stern, J. Umen, R. Willows, N. Wilson, S.L. Zimmer, J. Allmer, J. Balk, K. Bisova, C.J. Chen, M. Elias, K. Gendler, C. Hauser, M.R. Lamb, H. Ledford, J. C. Long, J. Minagawa, M.D. Page, J. Pan, W. Pootakham, S. Roje, A. Rose, E. Stahlberg, A.M. Terauchi, P. Yang, S. Ball, C. Bowler, C.L. Dieckmann, V. N. Gladyshev, P. Green, R. Jorgensen, S. Mayfield, B. Mueller-Roeber, S. Rajamani, R.T. Sayre, P. Brokstein, I. Dubchak, D. Goodstein, L. Hornick, Y. W. Huang, J. Jhaveri, Y. Luo, D. Martinez, W.C. Ngau, B. Otillar, A. Poliakov, A. Porter, L. Szajkowski, G. Werner, K. Zhou, I.V. Grigoriev, D.S. Rokhsar, A. R. Grossman, The Chlamydomonas genome reveals the evolution of key animal and plant functions, Science 318 (2007) 245-250.

[47] S. Xu, D. Guerra, U. Lee, E. Vierling, S-nitrosoglutathione reductases are low-copy number, cysteine-rich proteins in plants that control multiple developmental and defense responses in Arabidopsis, Front. Plant Sci. 4 (2013) 430

[48] T. Cheng, J. Chen, A.A. Ef, P. Wang, G. Wang, X. Hu, J. Shi, Quantitative proteomics analysis reveals that S-nitrosoglutathione reductase (GSNOR) and nitric oxide signaling enhance poplar defense against chilling stress, Planta 242 (2015) 1361-1390.

[49] P.C. Sanghani, W.F. Bosron, T.D. Hurley, Human glutathione-dependent formaldehyde dehydrogenase. Structural changes associated with ternary complex formation, Biochemistry 41 (2002) 15189-15194.

[50] L. Frungillo, M.J. Skelly, G.J. Loake, S.H. Spoel, I. Salgado, S-nitrosothiols regulate nitric oxide production and storage in plants through the nitrogen assimilation pathway, Nat. Commun. 5 (2014) 5401.

[51] T. Zhang, M. Ma, T. Chen, L. Zhang, L. Fan, W. Zhang, B. Wei, S. Li, W. Xuan, G. Noctor, Y. Han, Glutathione-dependent denitrosation of GSNOR1 promotes oxidative signalling downstream of H2 O2, Plant Cell Environ. 43 (2020) 1175-1191.

[52] D. Guerra, K. Ballard, I. Truebridge, E. Vierling, S-nitrosation of conserved cysteines modulates activity and stability of S-nitrosoglutathione reductase (GSNOR), Biochemistry 55 (2016) 2452-2464.

[53] N. Zhan, C. Wang, L. Chen, H. Yang, J. Feng, X. Gong, B. Ren, R. Wu, J. Mu, Y. Li, Z. Liu, Y. Zhou, J. Peng, K. Wang, X. Huang, S. Xiao, J. Zuo, S-nitrosylation targets GSNO reductase for selective autophagy during hypoxia responses in plants, Mol. Cell. 71 (2018) 142-154 e146.

[54] L. Chen, R. Wu, J. Feng, T. Feng, C. Wang, J. Hu, N. Zhan, Y. Li, X. Ma, B. Ren, J. Zhang, C.P. Song, J. Li, J.M. Zhou, J. Zuo, Transnitrosylation mediated by the non-canonical catalase ROG1 regulates nitric oxide signaling in plants, Dev. Cell 53 (2020) 444-457, e445.

[55] I. Kovacs, C. Holzmeister, M. Wirtz, A. Geerlof, T. Frohlich, G. Romling, G. T. Kuruthukulangarakoola, E. Linster, R. Hell, G.J. Arnold, J. Durner, C. Lindermayr, ROS-mediated inhibition of S-nitrosoglutathione reductase contributes to the activation of anti-oxidative mechanisms, Front. Plant Sci. 7 (2016) 1669.
[56] T. Ticha, J. Lochman, L. Cincalova, L. Luhova, M. Petrivalsky, Redox regulation of plant S-nitrosoglutathione reductase activity through post-translational modifications of cysteine residues, Biochem. Biophys. Res. Commun. 494 (2017) 27-33.

[57] X.G. Bai, J.H. Chen, X.X. Kong, C.D. Todd, Y.P. Yang, X.Y. Hu, D.Z. Li, Carbon monoxide enhances the chilling tolerance of recalcitrant Baccaurea ramiflora seeds via nitric oxide-mediated glutathione homeostasis, Free Radic. Biol. Med. 53 (2012) 710-720.

[58] L. Wei, B. Derrien, A. Gautier, L. Houille-Vernes, A. Boulouis, D. Saint-Marcoux, A. Malnoe, F. Rappaport, C. de Vitry, O. Vallon, Y. Choquet, F.A. Wollman, Nitric oxide-triggered remodeling of chloroplast bioenergetics and thylakoid proteins upon nitrogen starvation in Chlamydomonas reinhardtii, Plant Cell 26 (2014) 353-372.

[59] E. Sanz-Luque, F. Ocana-Calahorro, A. Llamas, A. Galvan, E. Fernandez, Nitric oxide controls nitrate and ammonium assimilation in Chlamydomonas reinhardtii, J. Exp. Bot. 64 (2013) 3373-3383.

[60] M. De Mia, S.D. Lemaire, Y. Choquet, F.A. Wollman, Nitric oxide remodels the photosynthetic apparatus upon S-starvation in Chlamydomonas reinhardtii, Plant Physiol. 179 (2019) 718-731.

[61] Z. Zalutskaya, L. Kochemasova, E. Ermilova, Dual positive and negative control of Chlamydomonas PII signal transduction protein expression by nitrate/nitrite and NO via the components of nitric oxide cycle, BMC Plant Biol. 18 (2018) 305.

[62] V. Calatrava, A. Chamizo-Ampudia, E. Sanz-Luque, F. Ocana-Calahorro, A. Llamas, E. Fernandez, A. Galvan, How Chlamydomonas handles nitrate and the nitric oxide cycle, J. Exp. Bot. 68 (2017) 2593-2602.

[63] X. Chen, D. Tian, X. Kong, Q. Chen, F.A. E, X. Hu, A. Jia, The role of nitric oxide signalling in response to salt stress in Chlamydomonas reinhardtii, Planta 244 (2016) 651-669.

[64] T.W. Hart, Some observations concerning the S-nitroso and S-phenylsulphonyl derivatives of L-cysteine and glutathione, Tetrahedron Lett. 26 (1985) 2013-2016.

[65] M. Pasquini, S. Fermani, D. Tedesco, C. Sciabolini, P. Crozet, M. Naldi, J. Henri, U. Vothknecht, C. Bertucci, S.D. Lemaire, M. Zaffagnini, F. Francia, Structural basis for the magnesium-dependent activation of transketolase from Chlamydomonas reinhardtii, Biochim. Biophys. Acta Gen. Subj. 1861 (2017) 2132-2145.

[66] P.C. Sanghani, W.I. Davis, L. Zhai, H. Robinson, Structure-function relationships in human glutathione-dependent formaldehyde dehydrogenase. Role of Glu-67 and Arg-368 in the catalytic mechanism, Biochemistry 45 (2006) 4819-4830.

[67] M.E. Pérez-Pérez, A. Mauriès, A. Maes, N.J. Tourasse, M. Hamon, S.D. Lemaire, C. H. Marchand, The deep thioredoxome in Chlamydomonas reinhardtii: new insights into redox regulation, Mol. Plant 10 (2017) 1107-1125.

[68] C.H. Marchand, S. Fermani, J. Rossi, L. Gurrieri, D. Tedesco, J. Henri, F. Sparla, P. Trost, S.D. Lemaire, M. Zaffagnini, Structural and biochemical insights into the reactivity of thioredoxin h1 from Chlamydomonas reinhardtii, Antioxidants (Basel) 8 (2019).

[69] Z. Shao, C. Borde, C.H. Marchand, S.D. Lemaire, P. Busson, J.M. Gozlan, A. Escargueil, V. Marechal, Detection of IgG directed against a recombinant form of Epstein-Barr virus BALF0/1 protein in patients with nasopharyngeal carcinoma, Protein Expr. Purif. 162 (2019) 44-50.

[70] M. Zaffagnini, S. Fermani, M. Calvaresi, R. Orru, L. Iommarini, F. Sparla, G. Falini, A. Bottoni, P. Trost, Tuning cysteine reactivity and sulfenic acid stability by protein microenvironment in glyceraldehyde-3-phosphate dehydrogenases of Arabidopsis thaliana, Antioxidants Redox Signal. 24 (2016) 502-517.

[71] M. Zaffagnini, M. Bedhomme, H. Groni, C.H. Marchand, C. Puppo, B. Gontero, C. Cassier-Chauvat, P. Decottignies, S.D. Lemaire, Glutathionylation in the photosynthetic model organism Chlamydomonas reinhardtii: a proteomic survey, Mol. Cell. Proteomics 11 (2012). M111 014142.

[72] M. Zaffagnini, C.H. Marchand, M. Malferrari, S. Murail, S. Bonacchi, D. Genovese, M. Montalti, G. Venturoli, G. Falini, M. Baaden, S.D. Lemaire, S. Fermani, P. Trost, Glutathionylation primes soluble glyceraldehyde-3-phosphate dehydrogenase for late collapse into insoluble aggregates, Proc. Natl. Acad. Sci. U. S. A. 116 (2019) 26057-26065.

[73] W. Kabsch, Xds, Acta Crystallogr D Biol Crystallogr 66 (2010) 125-132.

[74] P.R. Evans, G.N. Murshudov, How good are my data and what is the resolution? Acta Crystallogr D Biol Crystallogr 69 (2013) 1204-1214.

[75] A. Vagin, A. Teplyakov, Molecular replacement with MOLREP, Acta Crystallogr D Biol Crystallogr 66 (2010) 22-25.

[76] B.W. Matthews, Solvent content of protein crystals, J. Mol. Biol. 33 (1968) 491-497.

[77] G.N. Murshudov, P. Skubak, A.A. Lebedev, N.S. Pannu, R.A. Steiner, R. A. Nicholls, M.D. Winn, F. Long, A.A. Vagin, REFMAC5 for the refinement of macromolecular crystal structures, Acta Crystallogr D Biol Crystallogr 67 (2011) 355-367.

[78] P. Emsley, K. Cowtan, Coot: model-building tools for molecular graphics, Acta Crystallogr D Biol Crystallogr 60 (2004) 2126-2132.

[79] P.D. Adams, P.V. Afonine, G. Bunkoczi, V.B. Chen, I.W. Davis, N. Echols, J. J. Headd, L.W. Hung, G.J. Kapral, R.W. Grosse-Kunstleve, A.J. McCoy, N. W. Moriarty, R. Oeffner, R.J. Read, D.C. Richardson, J.S. Richardson, T. C. Terwilliger, P.H. Zwart, PHENIX: a comprehensive Python-based system for macromolecular structure solution, Acta Crystallogr D Biol Crystallogr 66 (2010) 213-221.

[80] V.B. Chen, W.B. Arendall 3rd, J.J. Headd, D.A. Keedy, R.M. Immormino, G. J. Kapral, L.W. Murray, J.S. Richardson, D.C. Richardson, MolProbity: all-atom 
structure validation for macromolecular crystallography, Acta Crystallogr D Biol Crystallogr 66 (2010) 12-21.

[81] A.C. Wallace, R.A. Laskowski, J.M. Thornton, LIGPLOT: a program to generate schematic diagrams of protein-ligand interactions, Protein Eng. 8 (1995) $127-134$.

[82] C.N. Pace, F. Vajdos, L. Fee, G. Grimsley, T. Gray, How to measure and predict the molar absorption coefficient of a protein, Protein Sci. 4 (1995) 2411-2423.

[83] I.H. van Stokkum, H.J. Spoelder, M. Bloemendal, R. van Grondelle, F.C. Groen, Estimation of protein secondary structure and error analysis from circular dichroism spectra, Anal. Biochem. 191 (1990) 110-118.

[84] N. Sreerama, R.W. Woody, Estimation of protein secondary structure from circular dichroism spectra: comparison of CONTIN, SELCON, and CDSSTR methods with an expanded reference set, Anal. Biochem. 287 (2000) 252-260.

[85] L. Whitmore, B.A. Wallace, DICHROWEB, an online server for protein secondary structure analyses from circular dichroism spectroscopic data, Nucleic Acids Res. 32 (2004) W668-W673.

[86] J.C. Bischof, X. He, Thermal stability of proteins, Ann. N. Y. Acad. Sci. 1066 (2005) 12-33.

[87] R.L. D'Ordine, R.S. Linger, C.J. Thai, V.J. Davisson, Catalytic zinc site and mechanism of the metalloenzyme PR-AMP cyclohydrolase, Biochemistry 51 (2012) 5791-5803.

[88] K. Engeland, J.O. Hoog, B. Holmquist, M. Estonius, H. Jornvall, B.L. Vallee Mutation of Arg-115 of human class III alcohol dehydrogenase: a binding site required for formaldehyde dehydrogenase activity and fatty acid activation, Proc. Natl. Acad. Sci. U. S. A. 90 (1993) 2491-2494.

[89] M. Estonius, J.O. Hoog, O. Danielsson, H. Jornvall, Residues specific for class II alcohol dehydrogenase. Site-directed mutagenesis of the human enzyme, Biochemistry 33 (1994) 15080-15085.

[90] B. Holmquist, B.L. Vallee, Human liver class III alcohol and glutathione dependent formaldehyde dehydrogenase are the same enzyme, Biochem. Biophys. Res. Commun. 178 (1991) 1371-1377.

[91] T. Ticha, L. Cincalova, D. Kopecny, M. Sedlarova, M. Kopecna, L. Luhova, M. Petrivalsky, Characterization of S-nitrosoglutathione reductase from Brassica and Lactuca spp. and its modulation during plant development, Nitric Oxide 68 (2017) 68-76.

[92] S.C. Askew, A.R. Butler, F.W. Flitney, G.D. Kemp, I.L. Megson, Chemical mechanisms underlying the vasodilator and platelet anti-aggregating properties of S-nitroso-N-acetyl-DL-penicillamine and S-nitrosoglutathione, Bioorg. Med. Chem. 3 (1995) 1-9.

[93] Z. Kolbert, J.B. Barroso, R. Brouquisse, F.J. Corpas, K.J. Gupta, C. Lindermayr, G. J. Loake, J.M. Palma, M. Petrivalsky, D. Wendehenne, J.T. Hancock, A forty year journey: the generation and roles of NO in plants, Nitric Oxide 93 (2019) 53-70.

[94] M.A. Scaife, G. Nguyen, J. Rico, D. Lambert, K.E. Helliwell, A.G. Smith, Establishing Chlamydomonas reinhardtii as an industrial biotechnology host, Plant J. 82 (2015) 532-546.

[95] R.H. Wijffels, O. Kruse, K.J. Hellingwerf, Potential of industrial biotechnology with cyanobacteria and eukaryotic microalgae, Curr. Opin. Biotechnol. 24 (2013) $405-413$.

[96] P. Crozet, F.J. Navarro, F. Willmund, P. Mehrshahi, K. Bakowski, K.J. Lauersen, M.E. Perez-Perez, P. Auroy, A. Gorchs Rovira, S. Sauret-Gueto, J. Niemeyer, B. Spaniol, J. Theis, R. Trosch, L.D. Westrich, K. Vavitsas, T. Baier, W. Hubner, F. de Carpentier, M. Cassarini, A. Danon, J. Henri, C.H. Marchand, M. de Mia, K. Sarkissian, D.C. Baulcombe, G. Peltier, J.L. Crespo, O. Kruse, P.E. Jensen, M. Schroda, A.G. Smith, S.D. Lemaire, Birth of a photosynthetic chassis: a MoClo toolkit enabling synthetic biology in the microalga Chlamydomonas reinhardtii, ACS Synth. Biol. 7 (2018) 2074-2086.

[97] K. Vavitsas, P. Crozet, M.H. Vinde, F. Davies, S.D. Lemaire, C.E. Vickers, The synthetic biology toolkit for photosynthetic microorganisms, Plant Physiol. 181 (2019) 14-27.
[98] M.A. Scaife, A.G. Smith, Towards developing algal synthetic biology, Biochem. Soc. Trans, 44 (2016) 716-722.

[99] A. Hemschemeier, M. Duner, D. Casero, S.S. Merchant, M. Winkler, T. Happe, Hypoxic survival requires a 2-on-2 hemoglobin in a process involving nitric oxide, Proc. Natl. Acad. Sci. U. S. A. 110 (2013) 10854-10859.

[100] M. Becana, I. Yruela, G. Sarath, P. Catalan, M.S. Hargrove, Plant hemoglobins: a journey from unicellular green algae to vascular plants, New Phytol. 227 (2020) $1618-1635$.

[101] W. Pokora, A. Aksmann, A. Bascik-Remisiewicz, A. Dettlaff-Pokora, M. Rykaczewski, M. Gappa, Z. Tukaj, Changes in nitric oxide/hydrogen peroxide content and cell cycle progression: study with synchronized cultures of green alga Chlamydomonas reinhardtii, J. Plant Physiol. 208 (2017) 84-93.

[102] H. Berger, M. De Mia, S. Morisse, C.H. Marchand, S.D. Lemaire, L. Wobbe, O. Kruse, A light switch based on protein S-nitrosylation fine-tunes photosynthetic light harvesting in Chlamydomonas, Plant Physiol. 171 (2016) 821-832.

[103] C.T. Stomberski, D.T. Hess, J.S. Stamler, Protein S-nitrosylation: determinants of specificity and enzymatic regulation of S-Nitrosothiol-Based signaling, Antioxidants Redox Signal. 30 (2019) 1331-1351.

[104] S.D. Lemaire, J.M. Richardson, A. Goyer, E. Keryer, J.M. Lancelin, G. I. Makhatadze, J.P. Jacquot, Primary structure determinants of the $\mathrm{pH}-$ and temperature-dependent aggregation of thioredoxin, Biochim. Biophys. Acta 1476 (2000) 311-323.

[105] K. Becker, M. Gui, R.H. Schirmer, Inhibition of human glutathione reductase by Snitrosoglutathione, Eur. J. Biochem. 234 (1995) 472-478.

[106] W. Maret, Y. Li, Coordination dynamics of zinc in proteins, Chem. Rev. 109 (2009) 4682-4707.

[107] D.K. Wilson, F.A. Quiocho, A pre-transition-state mimic of an enzyme: X-ray structure of adenosine deaminase with bound 1-deazaadenosine and zincactivated water, Biochemistry 32 (1993) 1689-1694.

[108] F.X. Gomis-Ruth, W. Stocker, R. Huber, R. Zwilling, W. Bode, Refined 1.8 A X-ray crystal structure of astacin, a zinc-endopeptidase from the crayfish Astacus astacus L. Structure determination, refinement, molecular structure and comparison with thermolysin, J. Mol. Biol. 229 (1993) 945-968.

[109] A.G. Daniel, N.P. Farrell, The dynamics of zinc sites in proteins: electronic basis for coordination sphere expansion at structural sites, Metallomics 6 (2014) $2230-2241$.

[110] K.A. McCall, C. Huang, C.A. Fierke, Function and mechanism of zinc metalloenzymes, J. Nutr. 130 (2000) 1437S-1446S.

[111] M.A. Holmes, B.W. Matthews, Binding of hydroxamic acid inhibitors to crystalline thermolysin suggests a pentacoordinate zinc intermediate in catalysis, Biochemistry 20 (1981) 6912-6920.

[112] L. Michelet, T. Roach, B.B. Fischer, M. Bedhomme, S.D. Lemaire, A. KriegerLiszkay, Down-regulation of catalase activity allows transient accumulation of a hydrogen peroxide signal in Chlamydomonas reinhardtii, Plant Cell Environ. 36 (2013) 1204-1213.

[113] N. Shao, C.F. Beck, S.D. Lemaire, A. Krieger-Liszkay, Photosynthetic electron flow affects $\mathrm{H}(2) \mathrm{O}(2)$ signaling by inactivation of catalase in Chlamydomonas reinhardtii, Planta 228 (2008) 1055-1066.

[114] M. Zaffagnini, S. Fermani, A. Costa, S.D. Lemaire, P. Trost, Plant cytoplasmic GAPDH: redox post-translational modifications and moonlighting properties, Front. Plant Sci. 4 (2013) 450.

[115] X. Robert, P. Gouet, Deciphering key features in protein structures with the new ENDscript server, Nucleic Acids Res. 42 (2014) W320-W324.

[116] F. Sievers, A. Wilm, D. Dineen, T.J. Gibson, K. Karplus, W. Li, R. Lopez, H. McWilliam, M. Remmert, J. Soding, J.D. Thompson, D.G. Higgins, Fast, scalable generation of high-quality protein multiple sequence alignments using Clustal Omega, Mol. Syst. Biol. 7 (2011) 539. 